\title{
Geographic heterogeneity in the outcomes of patients receiving immune checkpoint inhibitors for advanced solid tumors: a meta- analysis
}

\author{
Manyu Li", Jiannan Yao", Huiyun Zhang, Yang Ge, Guangyu An \\ Beijing Chao-Yang Hospital, Capital Medical University, Department of Oncology, Beijing, China \\ Contributions: (I) Conception and design: M Li, Y Ge, G An; (II) Administrative support: J Yao, Y Ge, G An; (III) Provision of study materials or \\ patients: M Li, J Yao, H Zhang; (IV) Collection and assembly of data: M Li, J Yao, H Zhang; (V) Data analysis and interpretation: M Li, J Yao; (VI) \\ Manuscript writing: All authors; (VII) Final approval of manuscript: All authors. \\ "These authors contributed equally to this work. \\ Correspondence to: Yang Ge MD, PhD; Guangyu An MD, PhD. No. 8, South Road of Workers Stadium, Chaoyang District, Beijing 100020, China; \\ Department of Oncology, Beijing Chao-Yang Hospital, Capital Medical University, Beijing 100020, China. Email: interna-1@163.com; agybjcy@163.com.
}

Background: Little is known about the effect of geographic location on efficacy of immune checkpoint inhibitors (ICI). We performed a systematic review and meta-analysis to assess the heterogeneity of ICI efficacy between different geographic locations.

Methods: We searched PubMed, EMBASE, and the Cochrane Library through October 2019 for phase III randomized controlled trials (RCT) that provided sufficient data for hazard ratio (HR) and $95 \%$ confidence interval (CI) of overall survival (OS) or progression-free survival (PFS) according to designated geographic region. We calculated pooled HRs and 95\% CIs for North American, European and Asian cancer patients, and assessed data heterogeneity using subgroup and sensitivity analysis. The INPLASY registration number was INPLASY202050062.

Results: Of 10151 publications identified in our research, 17 RCTs including 7462 patients met our selection criteria. The pooled HRs for OS of North American, European and Asian patients were 0.67 (95\% CI: 0.57 to 0.78 ), 0.72 (95\% CI: 0.64 to 0.81 ), and 0.74 (95\% CI: 0.66 to 0.84 ) respectively; the pooled HRs for PFS of North American, European and Asian patients were 0.58 (95\% CI: 0.49 to 0.69), 0.61 (95\% CI: 0.41 to 0.90 ), and 0.87 (95\% CI: 0.38 to 1.99 ) respectively. Both anti-PD-1 inhibitors and anti-PD-L1 inhibitors showed clinical benefit in North American and European arms while anti-PD-L1 inhibitors failed to show benefit in Asian arms.

Conclusions: Our meta-analysis indicates that the magnitude of benefit from ICI varies in North America, Europe, and Asia. Asian patients experience inferior outcomes compared to Western patients. Notably, antiPD-L1 therapies do not result in survival improvements in Asian patients.

Keywords: Geographic location; immune checkpoint inhibitors (ICI); meta-analysis; programmed death-1 (PD-1) inhibitor; programmed death-ligand 1 (PD-L1) inhibitor

Submitted Apr 10, 2020. Accepted for publication Sep 20, 2020.

doi: $10.21037 /$ tcr-20-1800

View this article at: http://dx.doi.org/10.21037/tcr-20-1800

\section{Introduction}

Immune checkpoint inhibitors (ICI) have radically changed the treatment modalities for a wide range of tumor types $(1,2)$. Currently, seven ICI have been approved for cancer treatment. These agents can be divided into three main classes: the cytotoxic T-lymphocyteassociated protein 4 (CTLA-4) inhibitor ipilimumab; the programmed death-1 (PD-1) inhibitors, nivolumab, 
pembrolizumab and cemiplimab; the programmed deathligand 1 (PD-L1) inhibitors, avelumab, durvalumab, and atezolizumab (3). Since the CTLA-4 inhibitor ipilimumab was approved on 28 March 2011 for the treatment of unresectable melanoma (4), the application of ICI has brought about dramatic clinical benefit to patients with melanoma or several other types of malignancies (5). It is noteworthy that since 2015 the combination of CTLA4 inhibitor and PD-1/PD-L1 inhibitor have shown magnificent efficacy in patients with non-small cell lung cancer (NSCLC) $(6,7)$, small cell lung cancer (SCLC) (8), renal cell cancer (RCC) (9), melanoma (10) and microsatellite instability (MSI)-high colorectal cancer (11) in comparison to ICI monotherapy. Despite unprecedented rates of longlasting clinical responses of ICI, these novel drugs have been widely used in routine clinical practice in geographic locations where large-scale clinical trials have not been carried out to prove their efficacy and safety. Different populations display differential sensitivity and safety profiles to different treatments. Such discrepancies have been identified in chemotherapy and targeted therapy (12-14). Moreover, differences in exposure to carcinogens, lifestyle, and dietary habits all may exert an impact on the variation of immunotherapy efficacy (15). It has been reported that the PD-1 inhibitors were more efficacious in smoking NSCLC patients (16). Despite a series of promising biomarkers such as PD-L1 tumor expression, tumor-infiltrating lymphocyte (TIL) status, and tumor mutational burden (TMB) for predicting ICI response, it is difficult to predict the wideranging clinical benefits precisely without using a broad set of biomarkers due to the complexity of the antitumor immune response and the heterogeneity of the patients. Identifying regional disparities may provide new ideas for selecting patients precisely and establishing individualized treatments (17). Despite its novelty and widespread use in Asia, few studies have assessed regional differences in immunotherapy outcomes. In this study, we performed a meta-analysis based on phased III trials to assess whether there was a region-dependent influence on patients with solid tumors treated with ICI. Also, detailed subgroup analyses according to cancer type, setting line of treatment, class of ICI were performed to reveal the heterogeneity. We present the following article in accordance with the PRISMA reporting checklist (available at http://dx.doi.org/10.21037/tcr-20-1800).

\section{Methods}

This study was performed according to the Preferred
Reporting Items for Systematic Reviews and Meta-Analyses (PRISMA) Statement (18) and the guidelines of the Cochrane Handbook (19). The protocol for this systematic review was registered on INPLASY (INPLASY202050062) and is available in full on the inplasy.com (https://doi. org/10.37766/inplasy2020.5.0062).

\section{Search strategy}

Articles that reported the association between geographic region and outcomes of cancer patients treated with ICI were independently searched by two reviewers (Manyu Li and Huiyun Zhang) in PubMed, EMBASE, and the Cochrane Library from their inception date to October 2019. The following keywords were used: "neoplasm", "malignant neoplasm", "carcinoma", "nivolumab", "pembrolizumab", "cemiplimab", "pidilizumab", "cetrelimab", "camrelizumab", "toripalimab", "sintilimab", "tislelizumab", "durvalumab", "atezolizumab", "avelumab", "bintrafusp alfa", "envafolimab", “ipilimumab", "randomized controlled trial." We expanded our search by reviewing abstracts and presentations from major conferences, including the American Society of Clinical Oncology (ASCO) and European Society for Medical Oncology (ESMO) meeting, in order to make sure that all eligible articles were screened. Finally, references to the studies included in the final selection were also checked. There was no language limitation in the literature search, and the process is presented in Table S1.

\section{Study selection}

The inclusion criteria were as follows: (I) phase III randomized controlled trial (RCT); (II) in the experimental arm, ICI (anti-PD-1 inhibitors or anti-PD-L1 inhibitors or anti-CTLA-4 inhibitors) were applied alone or in combination with other drugs, either immunological drug or chemotherapy; (III) the control regimen cannot include ICI unless it is a standard therapy; (IV) studies provided efficacy data of patients from North America, Europe, and Asia, respectively, and the data was required to include hazard ratio (HR) and $95 \%$ confidence interval (CI) of overall survival (OS) or progression-free survival (PFS). Criteria for excluding studies were as follows: (I) nonrandomized studies; (II) phase I or phase II studies; (III) studies not published in English; (IV) hematologic malignancy studies; (V) reviews, meta-analyses, case reports, comments, editorials, letters, expert consensuses, 
guidelines, or animal research; (VI) insufficient data about the OS and PFS of the designated geographic region. We only included the latest reports with sufficient efficacy data available and previous publications were discarded. Two independent reviewers (Manyu Li, Jiannan Yao) screened titles and abstracts of the literature search catalog to select potentially proper articles, then read over full texts to check the eligibility. Any discrepancy between two reviewers in the literature search and selection was solved through discussion or determined by a third reviewer (Yang Ge).

\section{Data extraction}

The following information was acquired from the selected studies: (I) study characteristics: publication year, first author, study design, setting line of treatment, type of cancer, and treatment regimens of each study arm. (II) Study population: median age, age range, and number of patients treated in each study arm. (III) Study outcomes: HR and 95\% CI for OS and/or PFS in the overall population, HR and $95 \%$ CI for OS and/or PFS in patients from North America, Europe, and Asia. Two investigators (Manyu Li, Jiannan Yao) independently extracted data from the studies, and all disagreements were resolved via discussion or consultation with the third investigator (Guangyu An).

\section{Quality assessment}

The study quality was evaluated using the Cochrane Collaboration's "Risk of bias" tool (20). The criteria included randomized sequence generation, allocation concealment, blinding of patients, personnel and outcome assessors, incomplete outcome data, selective outcome reporting, and other bias. We designated the risk of each item as low, high, or unclear. Two authors independently assessed the risk of bias, and all discrepancies were resolved by discussion with the third author until achieving consensus among the three authors. The assessment of risk is summarized in Figures S1,S2.

\section{Statistical analysis}

The pooled HR and 95\% CI of OS and PFS for patients from Asia, Europe, and North America were calculated, with $H R<1.0$ manifesting a better outcome in the experimental arm. We used the Q test and $\mathrm{I}^{2}$ statistics to assess the heterogeneity among the RCTs. When the two primary indicators are in specific ranges $(\mathrm{P}>0.1$ and
$\left.\mathrm{I}^{2}<50 \%\right)$, it was considered to show that no significant heterogeneity could be found between studies, and the fixed-effect model should be applied. If there was significant heterogeneity between the studies $\left(\mathrm{P}<0.1\right.$ or $\left.\mathrm{I}^{2}>50 \%\right)$, we analyzed them through the random-effects model (19). To explore the source of heterogeneity, subgroup analysis was carried out according to the class of ICI, cancer type, and the setting line of treatment where possible. Publication bias was assessed by funnel plots. Furthermore, Begg's and Egger's tests were utilized to examine the publication bias across studies $(21,22)$. Sensitivity analysis was utilized to examine whether the results could have been influenced by a single study by removing one study at a time. Our metaanalysis was performed using Review Manager 5.3 and STATA 14 software. For combined analysis, a $\mathrm{P}<0.05$ was treated as statistically significant.

\section{Results}

\section{Identification and selection}

We identified 10,151 publications reporting on ICI applied in cancer treatment by searching relevant databases and other sources. After removing 1,106 duplicate studies, there were 9,045 articles left for preliminary screening of titles and abstracts, from which we selected 61 articles for fulltext assessment. A total of 8,984 articles were excluded for following reasons: case reports, guidelines, expert consensuses, clinical experience; letters, reviews, editorials, comments, news, notes, meta-analyses; not phase III RCT, not English paper, hematologic malignancies or lymphoma studies, or repeat presentations of participants captured by another study. After full-text review, 40 articles were excluded due to missing data according to patients' region subgroup, while two articles were not phase III RCT. Despite containing designated region survival data, two trials were excluded for the following reasons: CheckMate 227 only included patients with a high TMB, and the intervention arm of JAVELIN Renal 101 is a combination of ICI with axitinib which is not the first-line therapy for advanced renal-cell carcinoma. Finally, 17 phase III RCTs (23-39) were included in the meta-analysis. The flow diagram of the search and selection steps are shown in Figure 1.

\section{Characteristics of included studies and patients}

Among the 17 studies, five involved nivolumab 


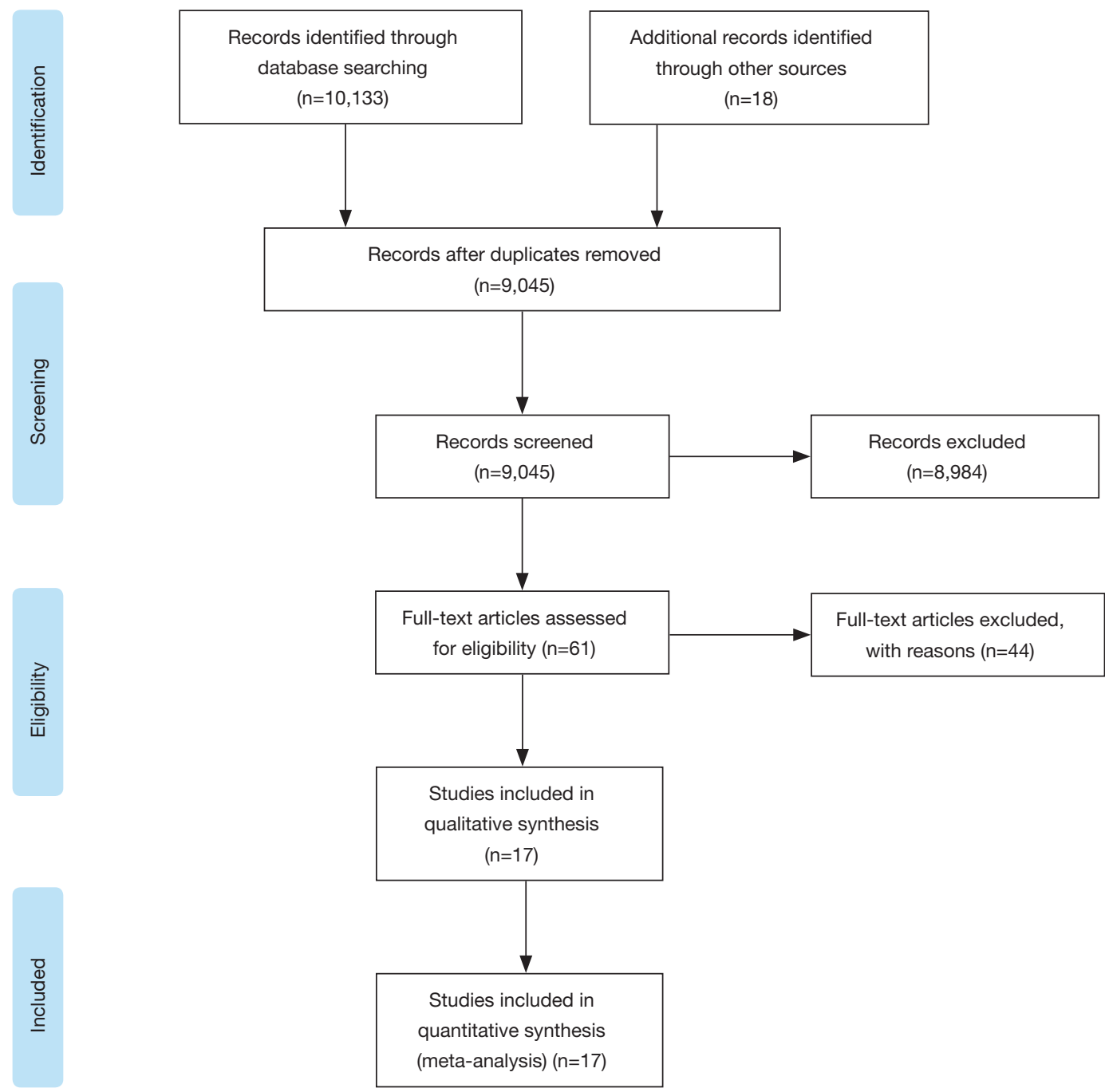

Figure 1 Flow diagram of study eligibility and selection process.

(23-27), five involved pembrolizumab (28,32,36-38), two involved durvalumab $(34,39)$, one each involved atezolizumab (35), avelumab (29), and ipilimumab (33), one compared combined treatment of nivolumab and ipilimumab with ICI alone (nivolumab or ipilimumab) (31), and one compared pembrolizumab with ipilimumab (30). The cancer types were respectively: lung cancer, eight trials $(23,24,34-39)$; melanoma, two trials $(30,31)$; gastric or gastro-oesophageal junction cancer, three trials (27-29); head and neck cancer, two trials $(26,32)$; RCC, one trial (25); and prostate cancer, one trial (33). The sample size in each study ranged from 272 to 2,075. Overall, 7,462 patients were enrolled in our meta-analysis, 2,073 patients from North America, 3,457 patients from Europe, and 1,932 patients from Asia. The main characteristics and results in each trial are presented in Table 1.

\section{Primary outcome: overall survival}

OS data stratified by regions were available in 17 studies. North American patients' pooled HR for OS using the random-effects model was 0.67 (95\% CI: 0.57 to 0.78 , $\mathrm{I}^{2}=47 \%, \mathrm{P}=0.03$; Figure $2 A$ ). The pooled HR from OS for European patients using the random-effects model was 0.72 (95\% CI: 0.64 to $0.81, \mathrm{I}^{2}=48 \%, \mathrm{P}=0.04$; Figure $2 B$ ). Since low heterogeneity $\left(\mathrm{I}^{2}=33 \%, \mathrm{P}=0.15\right)$ was observed between individual studies, we deployed the fixed-effects model to calculate the pooled HR of OS from Asian patients, and 


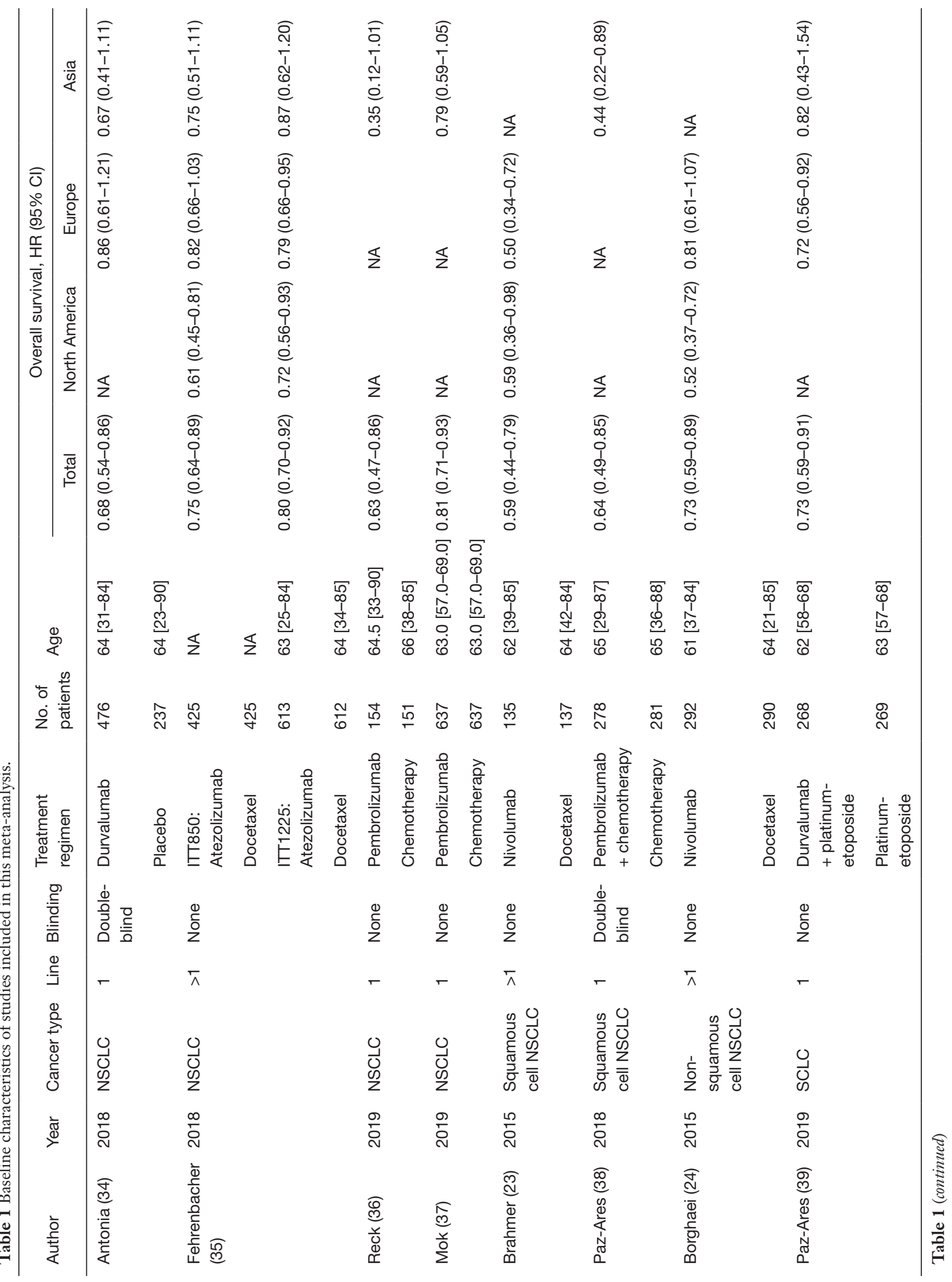




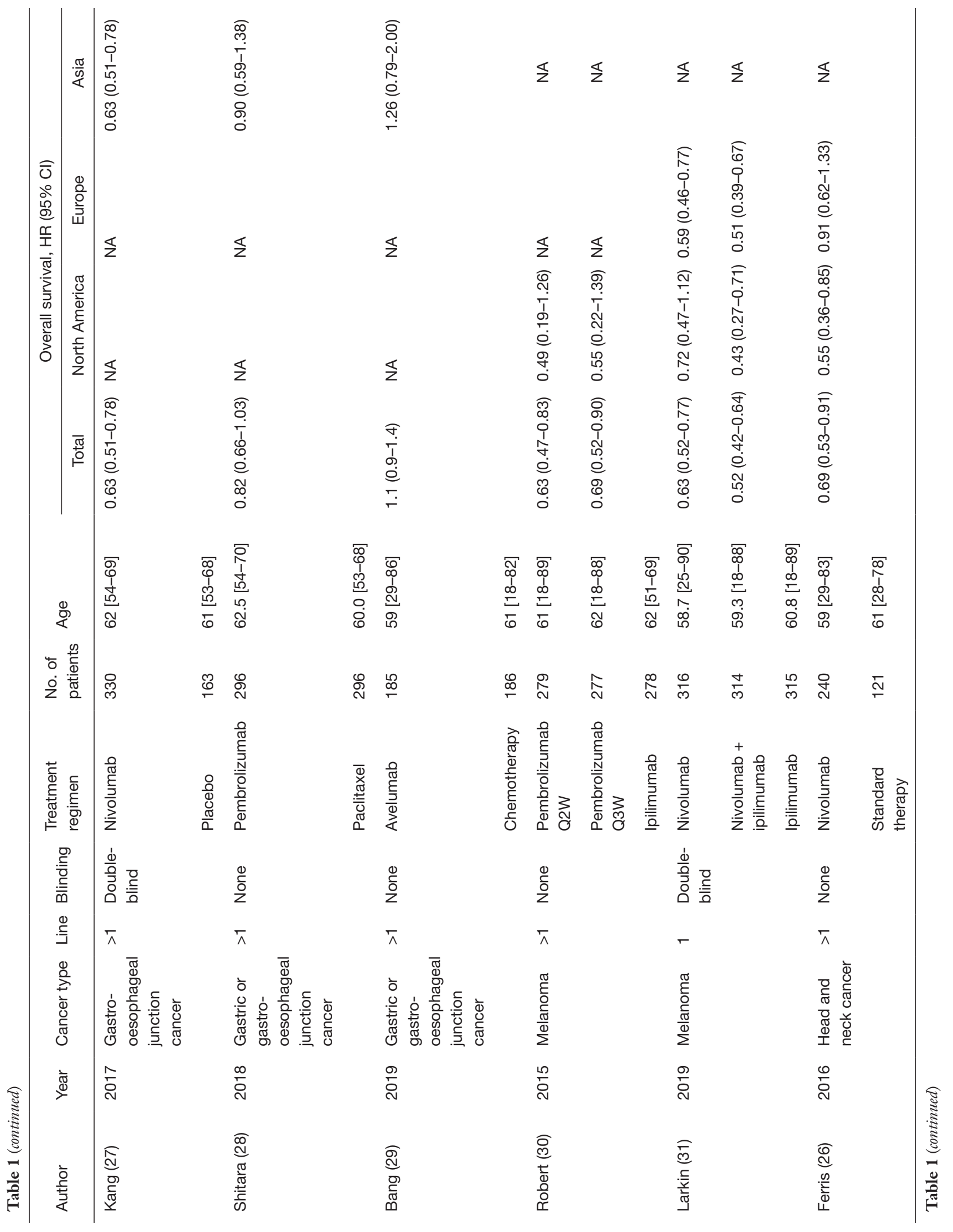




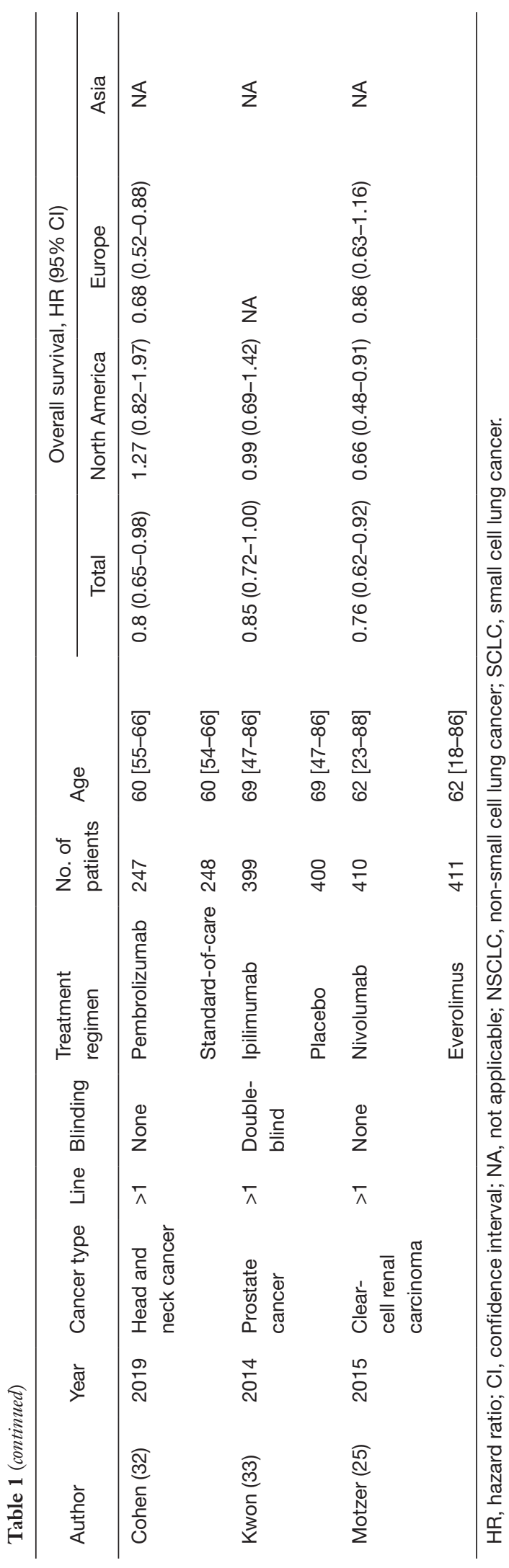

the result was 0.74 (95\% CI: 0.66 to 0.84 ; Figure 2 C).In summary, patients from North America, Europe, and Asia all showed a significantly reduced risk of death when treated with ICI compared to control. Despite no substantial differences in heterogeneity $\left(\mathrm{P}_{\text {heterogeneity }} \geq 0.05\right.$; Table 2$)$, when we collated the OS data of these three designated regions with each other, North American patients derived the best clinical benefit, European patients ranked second, and Asian patients derived the least clinical benefit.

\section{Secondary outcomes: progression-free survival}

Seven RCTs provided data on PFS according to geographic region. Based on the included trials, there was no heterogeneity within-study in the North American arm $\left(\mathrm{I}^{2}=0 \%, \mathrm{P}=0.62\right)$, suggesting that the pooled estimate should be deployed based on the fixed-effects model. However, there was high heterogeneity within-study in the European $\operatorname{arm}\left(\mathrm{I}^{2}=88 \%, \mathrm{P}<0.0001\right)$ and Asian $\operatorname{arm}\left(\mathrm{I}^{2}=93 \%\right.$, $\mathrm{P}<0.0001$ ), suggesting that the pooled estimate should be calculated based on the random-effects model. In summary, a significant improvement in PFS emerged exclusively in patients from North America (HR 0.58, 95\% CI: 0.49 to 0.69; Figure $3 A$ ) and Europe (HR 0.61, 95\% CI: 0.41 to 0.90; Figure $3 B$ ), but not in patients from Asia (HR 0.87, 95\% CI: 0.38 to 1.99 ; Figure $3 C$ ). When we compared the PFS data of these three designated regions with each other, the differences did not achieve statistical significance. $\left(\mathrm{P}_{\text {heterogeneity }} \geq 0.05\right.$; Table 2$)$

\section{Subgroup analyses}

In order to further explore the source of heterogeneity, subgroup analyses were conducted according to class of ICI applied in the intervention arm, cancer type and setting line of treatment. The detailed outcomes are shown in Table 3, and Figures S3-S5.

We found a statistically significant advantage in favor of anti-PD-1 inhibitors and anti-PD-L1 inhibitors in both North American (anti-PD-1 inhibitors: HR: 0.63, 95\% CI: 0.51 to 0.78 ; anti-PD-L1 inhibitors: HR: $0.67,95 \%$ CI: 0.55 to 0.82 ; Table 3) and European arms (anti-PD-1 inhibitors: HR: $0.67,95 \%$ CI: 0.57 to 0.80 ; anti-PD-L1 inhibitors: HR: $0.79,95 \%$ CI: 0.71 to 0.89 ; Table 3), while only antiPD-1 inhibitors had statistically significant differences in Asian arms (anti-PD-1 inhibitors: HR: 0.68, 95\% CI: 0.55 to 0.85 ; anti-PD-L1 inhibitors: HR: $0.85,95 \%$ CI: 0.70 
A

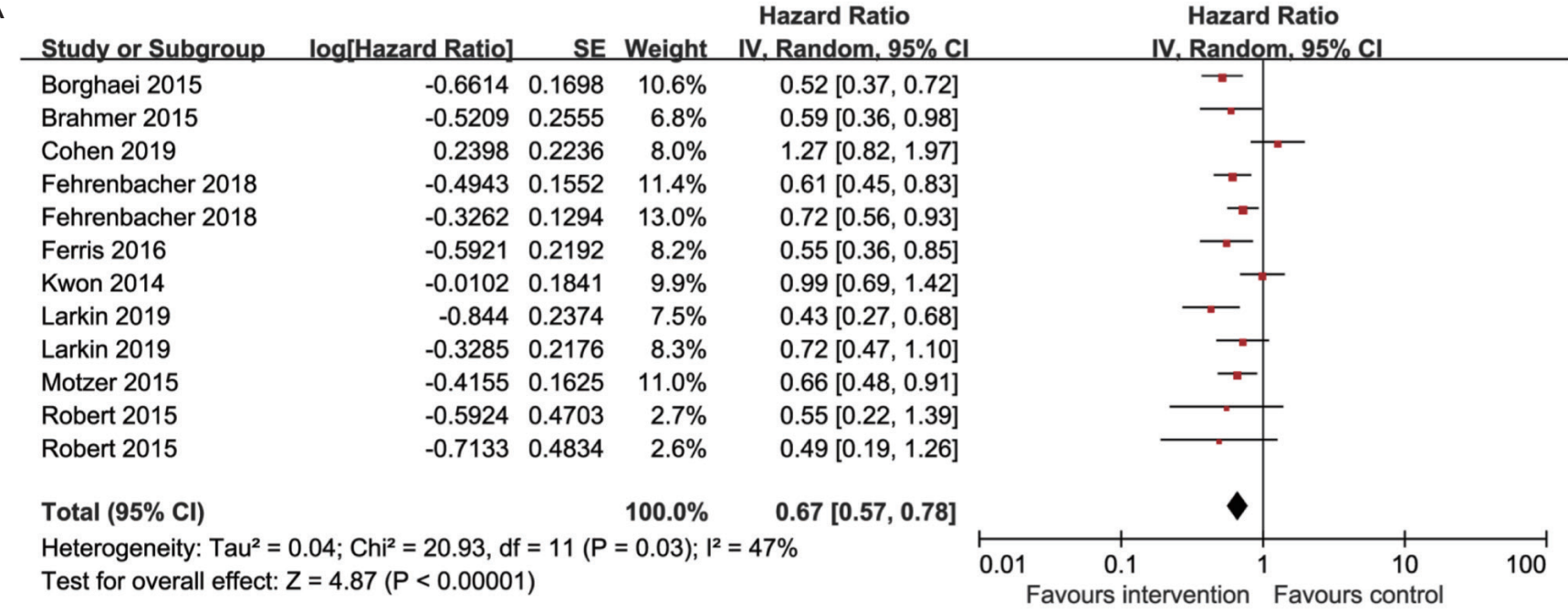

B

\begin{tabular}{|c|c|c|c|c|c|c|c|}
\hline Study or Subgroup & log[Hazard Ratio] & SE & Weight & $\begin{array}{l}\text { Hazard Ratio } \\
\text { IV. Random, } 95 \% \text { C }\end{array}$ & $\begin{array}{r}\text { Hazard } \\
\text { IV. Rando| }\end{array}$ & $\begin{array}{l}\text { rd Ratio } \\
\text { om. } 95 \% \mathrm{Cl}\end{array}$ & \\
\hline Antonia 2018 & -0.1508 & 0.1752 & $7.1 \%$ & $0.86[0.61,1.21]$ & $\Rightarrow$ & & \\
\hline Borghaei 2015 & -0.2133 & 0.1434 & $9.0 \%$ & $0.81[0.61,1.07]$ & $\Rightarrow$ & & \\
\hline Brahmer 2015 & -0.6931 & 0.1968 & $6.1 \%$ & $0.50[0.34,0.74]$ & - & & \\
\hline Cohen 2019 & -0.3909 & 0.1342 & $9.6 \%$ & $0.68[0.52,0.88]$ & - & & \\
\hline Fehrenbacher 2018 & -0.193 & 0.1135 & $11.3 \%$ & $0.82[0.66,1.03]$ & - & & \\
\hline Fehrenbacher 2018 & -0.2334 & 0.0929 & $13.1 \%$ & $0.79[0.66,0.95]$ & $=$ & & \\
\hline Ferris 2016 & -0.0964 & 0.1947 & $6.2 \%$ & $0.91[0.62,1.33]$ & & & \\
\hline Larkin 2019 & -0.5276 & 0.127 & $10.2 \%$ & $0.59[0.46,0.76]$ & $\mp$ & & \\
\hline Larkin 2019 & -0.6733 & 0.1369 & $9.4 \%$ & $0.51[0.39,0.67]$ & $=$ & & \\
\hline Motzer 2015 & -0.1508 & 0.1588 & $8.0 \%$ & $0.86[0.63,1.17]$ & & & \\
\hline Paz-Ares 2019 & -0.3316 & 0.1266 & $10.2 \%$ & $0.72[0.56,0.92]$ & $=$ & & \\
\hline Total $(95 \% \mathrm{Cl})$ & & & $100.0 \%$ & $0.72[0.64,0.81]$ & 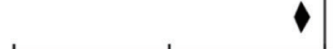 & & \\
\hline \multirow{2}{*}{\multicolumn{5}{|c|}{$\begin{array}{l}\text { Heterogeneity: } \mathrm{Tau}^{2}=0.02 ; \mathrm{Chi}^{2}=19.26, \mathrm{df}=10(P=0.04) ; I^{2}=48 \% \\
\text { Test for overall effect: } Z=5.67(P<0.00001)\end{array}$}} & 0.01 & 10 & 100 \\
\hline & & & & & Favours intervention & Favours control & \\
\hline Study or Subgroup & log[Hazard Ratio] & SE & Weight & $\begin{array}{l}\text { Hazard Ratio } \\
\text { IV. Fixed, } 95 \% \text { CI }\end{array}$ & $\begin{array}{l}\text { Hazard } \\
\text { IV, Fixed. }\end{array}$ & $\begin{array}{l}\text { d Ratio } \\
\text { d. } 95 \% \mathrm{Cl}\end{array}$ & \\
\hline Antonia 2018 & -0.3936 & 0.2541 & $5.8 \%$ & $0.67[0.41,1.11]$ & $\cdot 1$ & & \\
\hline Bang 2019 & 0.2287 & 0.237 & $6.7 \%$ & $1.26[0.79,2.00]$ & & & \\
\hline Fehrenbacher 2018 & -0.2845 & 0.1984 & $9.5 \%$ & $0.75[0.51,1.11]$ & $=$ & & \\
\hline Fehrenbacher 2018 & -0.1393 & 0.1728 & $12.6 \%$ & $0.87[0.62,1.22]$ & 7 & & \\
\hline Kang 2017 & -0.462 & 0.1078 & $32.3 \%$ & $0.63[0.51,0.78]$ & 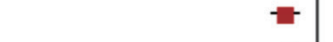 & & \\
\hline Mok 2019 & -0.2394 & 0.147 & $17.4 \%$ & $0.79[0.59,1.05]$ & -7 & & \\
\hline Paz-Ares 2018 & -0.8153 & 0.3565 & $3.0 \%$ & $0.44[0.22,0.89]$ & - & & \\
\hline Paz-Ares 2019 & -0.1985 & 0.3294 & $3.5 \%$ & $0.82[0.43,1.56]$ & & & \\
\hline Reck 2019 & -1.0552 & 0.5434 & $1.3 \%$ & $0.35[0.12,1.01]$ & & & \\
\hline Shitara 2018 & -0.1028 & 0.2168 & $8.0 \%$ & $0.90[0.59,1.38]$ & - & & \\
\hline Total $(95 \% \mathrm{Cl})$ & & & $100.0 \%$ & $0.74[0.66,0.84]$ & $\checkmark$ & & \\
\hline \multicolumn{5}{|c|}{$\begin{array}{l}\text { Heterogeneity: } \mathrm{Chi}^{2}=13.35, \mathrm{df}=9(P=0.15) ; I^{2}=33 \% \\
\text { Test for overall effect: } Z=4.83(P<0.00001)\end{array}$} & 0.01 & 1 & 100 \\
\hline
\end{tabular}

Figure 2 Forest plot of the hazard ratios and 95\% CI for overall survival in North American (A), European (B), Asian (C) patients assigned to intervention arm, compared with those assigned to the control arm. 
Table 2 Pooled hazard ratios for OS and PFS in North America, Europe, and Asia

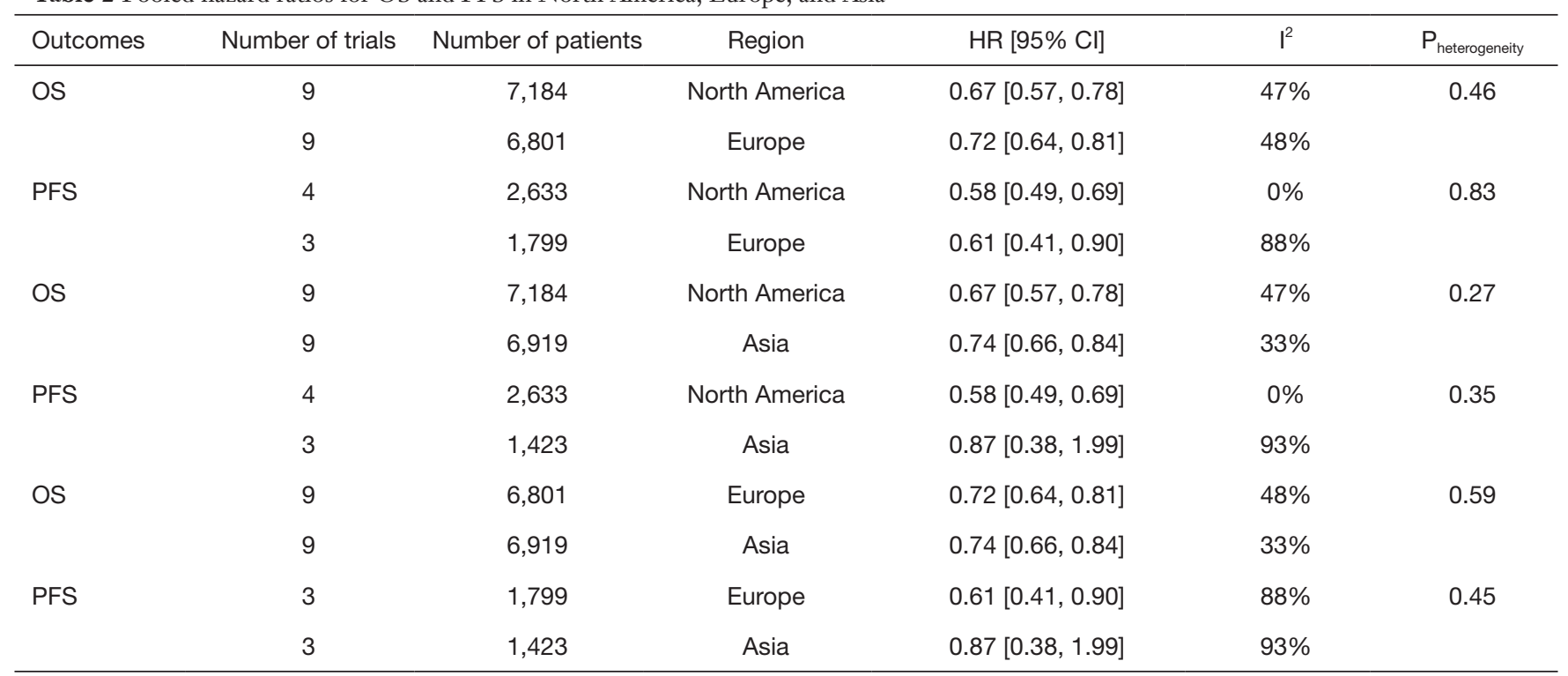

OS, overall survival; PFS, progression-free survival; $\mathrm{HR}$, hazard ratio; $\mathrm{Cl}$, confidence interval.

to 1.04; Table 3). Furthermore, there was a tendency for anti-PD-1 inhibitors to be more efficient compared with anti-PD-L1 inhibitors in all three designated geographic regions, despite no statistical significance.

Additionally, there was an evident region-independent trend in several types of cancer, such as lung cancer and melanoma which had significantly prolonged OS while other types of cancer such as head and neck cancer, prostate cancer and gastric or gastro-oesophageal junction cancer failed to acquire benefit from the administration of ICI. The detailed outcomes are shown in Table 3.

Regardless of geographic regions, ICI applied in firstline treatment (North American: HR: 0.56, 95\% CI: 0.34 to 0.93; European: HR: 0.65, 95\% CI: 0.53 to 0.80; Asian: HR: 0.58, 95\% CI: 0.42 to 0.79; Table 3) always brought more clinical benefit compared to those applied in subsequent lines (North American: HR: 0.69, 95\% CI: 0.58 to 0.82; European: HR: $0.77,95 \%$ CI: 0.69 to 0.86 ; Asian: HR: 0.82 , 95\% CI: 0.65 to 1.03 Table 3).

\section{Publication bias}

Slight asymmetry can be detected in funnel plots of the overall survival from North American arm, European arm, Asian arm, and their combination (Figure 4), which suggests the potential for publication bias. We performed Egger's test and Begg's test via STATA 14.0 software. The results are summarized in Table 4. All the p values were $>0.05$ after both tests, suggesting there was no significant publication bias in this meta-analysis.

\section{Sensitivity analysis}

In order to assess the potential for significant heterogeneity between different studies, we performed a sensitivity analysis (Figure S6). There was no significant difference after removing any single study, which supports the stability of the combined results and the rationality of the metaanalysis.

\section{Discussion}

Based on previous research, the interaction of genetic background and environment may lead to discrepancy in ICI efficiency in different regions (40). Given few clinical trials that assessed geographic regions as a potential factor affecting the efficacy of ICI, we performed a systematic review and meta-analysis of phase III RCTs to explore the clinical efficacy of ICI between North America, Europe, and Asia.

In a previous meta-analysis by Wang et al. (40), 14 phase II/III trials with ICI applied in advanced cancer patients were included. Compared with the aforementioned study, all the studies we included are phase III RCTs which are sufficiently powered to detect differences. Additionally, phase III trials ensure longer follow-up. In order to evaluate 


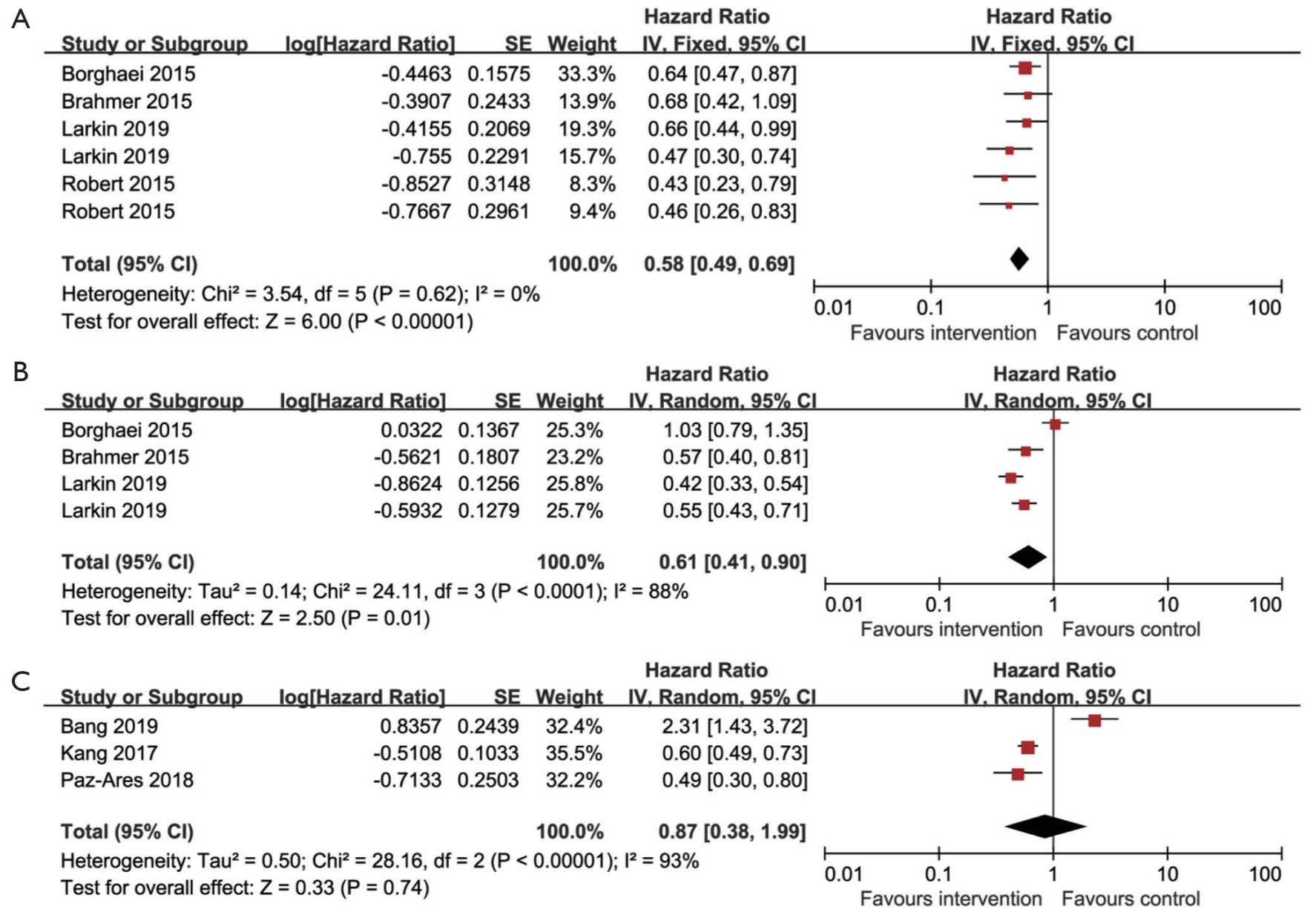

Figure 3 Forest plot of the hazard ratios and 95\% CI for progression-free survival in North American (A), European (B), Asian (C) patients assigned to intervention arm, compared with those assigned to the control arm.

the heterogeneity of efficacy of ICI more comprehensively, our meta-analysis not only included trials for anti-PD-1/ anti-PD-L1 inhibitors but also anti-CTLA-4 inhibitors. Importantly, we found that with the addition of extensive new Phase III trial data, the significant difference in OS between North American and European ICI-treated patients disappeared. This could be explained by the inclusion of more high-quality RCTs and longer follow-up. In our expanded analysis, Asian patients gained the least OS advantage among all three designated geographic locations. Moreover, a benefit in PFS was observed in all three regions in the Wang et al. study, while a benefit in PFS was observed only in North America and Europe in our study. In conclusion, our data indicated that ICI were less effective in Asia compared to North America and Europe.

The heterogeneity across included RCTs mainly resulted from class of ICI applied in the intervention arm, cancer type, and line of treatment. Therefore, we performed subgroup analyses and sensitivity analyses to determine sources of heterogeneity. To elaborate the benefit regarding the class of ICI applied, subgroup analyses of anti-PD-1 inhibitors or anti-PD-L1 inhibitors were performed in the three designated geographic regions. Anti-PD-1 inhibitors led to outcomes with statistical significance in North America, Europe, and Asia, while anti-PD-L1 inhibitors only had a statistically significant difference in North America and Europe. This evidence for the inferiority of efficacy of anti-PD-L1 inhibitors in Asia invites critical interpretation. The different mechanisms of action of anti-PD-L1 inhibitors and anti-PD-1 inhibitors may help provide a biologic rationale for this finding (41). Theoretically, the PD-1 antibody can bind to PD-1 protein 
Table 3 Pooled hazard ratios and 95\% CI of overall survival according to class of ICI, cancer type, and the setting line of ICI treatment

\begin{tabular}{|c|c|c|c|c|c|c|}
\hline Analysis & Region & $\mathrm{N}$ & \multicolumn{2}{|c|}{ Random-effects model } & \multicolumn{2}{|c|}{ Heterogeneity } \\
\hline \multirow[t]{3}{*}{ PD-1 } & All & 12 & $0.66[0.59,0.73]$ & $<0.00001$ & $44 \%$ & 0.02 \\
\hline & North America & 7 & $0.63[0.51,0.78]$ & $<0.0001$ & $46 \%$ & 0.06 \\
\hline & Europe & 6 & $0.67[0.57,0.80]$ & $<0.00001$ & $57 \%$ & 0.03 \\
\hline \multirow[t]{4}{*}{ PD-L1 } & All & 4 & $0.78[0.71,0.85]$ & $<0.00001$ & $0 \%$ & 0.56 \\
\hline & North America & 1 & $0.67[0.55,0.82]$ & $<0.0001$ & $0 \%$ & 0.41 \\
\hline & Europe & 3 & $0.79[0.71,0.89]$ & $<0.0001$ & $0 \%$ & 0.83 \\
\hline & Asia & 4 & $0.85[0.70,1.04]$ & 0.11 & $2 \%$ & 0.40 \\
\hline \multirow{2}{*}{ Lung cancer } & Europe & 5 & $0.76[0.68,0.86]$ & $<0.00001$ & $17 \%$ & 0.31 \\
\hline & Asia & 6 & $0.75[0.63,0.88]$ & 0.0006 & $0 \%$ & 0.50 \\
\hline \multirow[t]{3}{*}{ Melanoma } & All & 2 & $0.55[0.48,0.65]$ & $<0.00001$ & $0 \%$ & 0.66 \\
\hline & North America & 2 & $0.56[0.42,0.74]$ & $<0.0001$ & $0 \%$ & 0.45 \\
\hline & Europe & 1 & $0.55[0.46,0.66]$ & $<0.00001$ & $0 \%$ & 0.44 \\
\hline \multirow[t]{3}{*}{ Head and neck cancer } & All & 2 & $0.80[0.58,1.10]$ & 0.17 & $67 \%$ & 0.03 \\
\hline & North America & 2 & $0.83[0.37,1.89]$ & 0.66 & $86 \%$ & 0.007 \\
\hline & Europe & 2 & $0.76[0.58,1.00]$ & 0.05 & $33 \%$ & 0.22 \\
\hline \multirow{2}{*}{ First-line } & Europe & 3 & $0.65[0.53,0.80]$ & $<0.0001$ & $56 \%$ & 0.08 \\
\hline & Asia & 5 & $0.58[0.42,0.79]$ & 0.0006 & $0 \%$ & 0.44 \\
\hline \multirow[t]{4}{*}{ Subsequent line } & All & 11 & $0.74[0.68,0.82]$ & $<0.00001$ & $41 \%$ & 0.03 \\
\hline & North America & 8 & $0.69[0.58,0.82]$ & $<0.0001$ & $47 \%$ & 0.05 \\
\hline & Europe & 6 & $0.77[0.69,0.86]$ & $<0.00001$ & $19 \%$ & 0.29 \\
\hline & Asia & 4 & $0.82[0.65,1.03]$ & 0.09 & $54 \%$ & 0.07 \\
\hline
\end{tabular}

$\mathrm{HR}$, hazard ratio; $\mathrm{Cl}$, confidence interval; ICl, immune checkpoint inhibitors; HR, hazard ratio.

on T cells, which means that it blocks the binding of PD-1 to PD-L1 and PD-L2 at the same time. However, the PDL1 antibody can only block the binding of PD-1 to PDL1, which means the intact interaction of PD-1 and PD-L2 may inhibit the activation of $\mathrm{T}$ cells. Therefore, treatment with anti-PD-L1 may provide an opportunity for tumors escaping from the antitumor immune response through the PD-1/PD-L2 axis. Indeed, PD-L2 expression status predicts the clinical benefit of ICI treatment independent of PD-L1 expression status $(42,43)$. Since all RCTs 

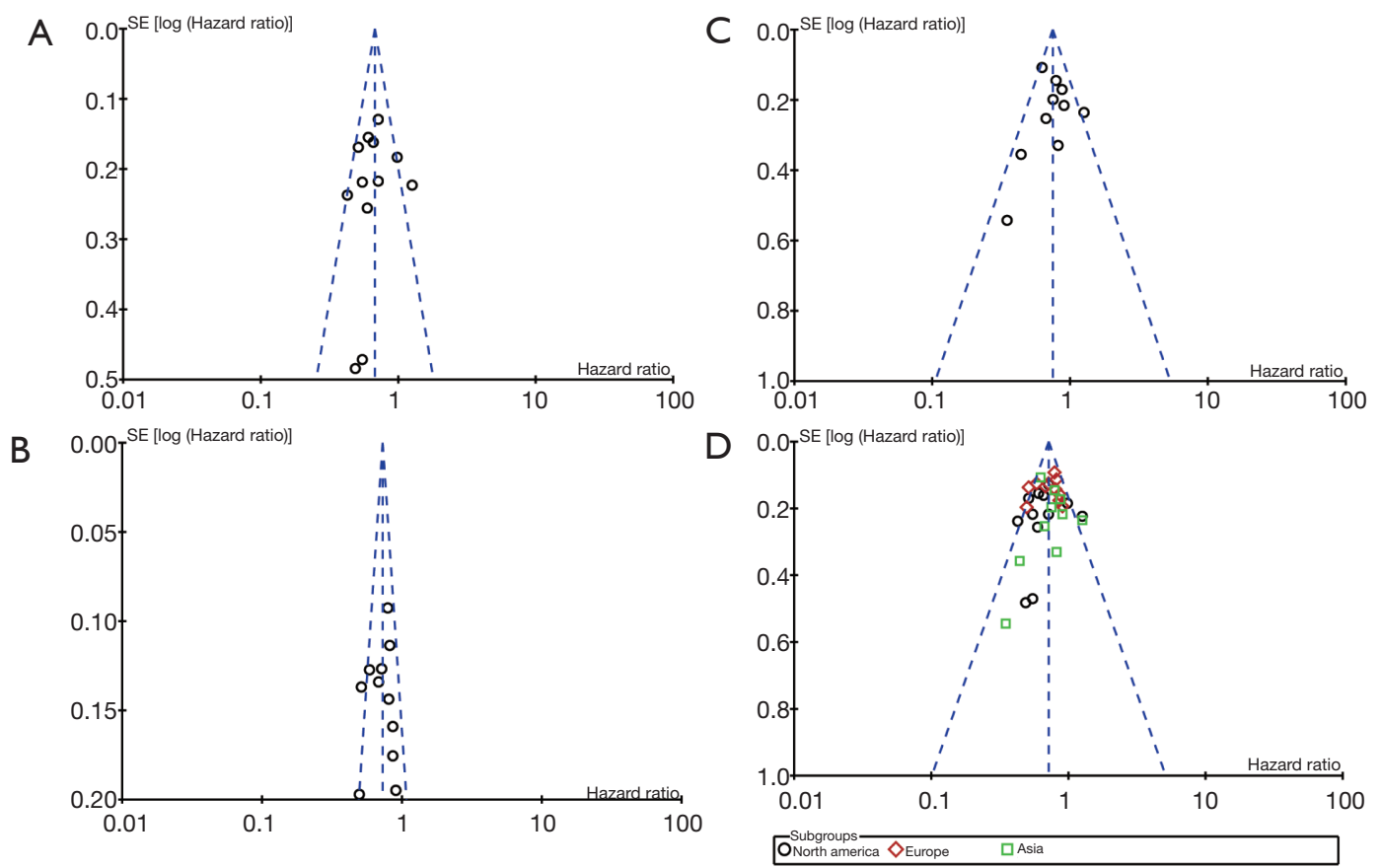

Figure 4 Funnel plots for overall survival data from North American (A), European (B), Asian (C) and combined arms (D) in included RCTs for the visual detection of systematic publication bias and small study effect. RCT, randomized controlled trial.

Table 4 Evaluation of publication bias in overall survival with Begg's test and Egger's test

\begin{tabular}{|c|c|c|c|c|c|c|c|c|}
\hline Outcomes & Trials & No. of patients & Region & $\mathrm{HR}(95 \% \mathrm{Cl})$ & \multicolumn{2}{|c|}{ Begg's test } & \multicolumn{2}{|c|}{ Egger's test } \\
\hline OS & 9 & 7,184 & North America & $0.67[0.57,0.78]$ & 0.34 & 0.732 & -0.50 & 0.625 \\
\hline os & 9 & 6,801 & Europe & $0.72[0.64,0.81]$ & 0.00 & 1.000 & -0.43 & 0.679 \\
\hline os & 9 & 6,919 & Asia & $0.74[0.66,0.84]$ & 0.54 & 0.592 & -0.06 & 0.954 \\
\hline
\end{tabular}

$\mathrm{HR}$, hazard ratio; $\mathrm{Cl}$, confidence interval; OS, overall survival.

except one included in the Asian subgroup were studies of NSCLC and GC, moderate to high PD-L2 expression was found in NSCLC and GC patients, which strengthens our observation of the poor performance of anti-PD-L1 compared with anti-PD-1 in the Asian subgroup. However, due to the absence of head-to-head clinical trial data, these suggestive findings should be interpreted with caution.

To further interpret the disparate results for anti-PD-L1 inhibitor efficacy in Asia compared to Western regions, we reviewed each relevant RCT individually. RCTs with North American subgroups displayed improved OS in all involved patients, not just in North American regions.
A similar finding was observed in studies with European subgroups with a single exception (34). However, the most striking result emerged with the Asian subgroup. With one exception demonstrating a failure to improve OS in both overall participants and Asian subgroup (29), the other RCTs demonstrated improved OS in all participants but not in the Asian subgroup. This finding is notable because it indicates that global OS data may hide disparities in ICI efficacy between Asian and Western countries.

In general, clinical trials for western medicine are firstly carried out in western countries. The assessment of efficacy and toxicity in other regions are usually conducted 
subsequently. However, the discrepancies in efficacy and safety profiles vary widely between various regions. As reported, approximately $20 \%$ of new agents approved between 2010-2015 displayed variations in response and/or exposure among ethnic/racial groups, leading to region-specific recommendations for prescribing in some cases (44). Additionally, it has been demonstrated that ethnic differences in clinical efficacy exist in cancer patients receiving targeted therapy or chemotherapy $(45,46)$, it is also highly likely that the efficiency of patients undergoing immunotherapy varies among different geographic location.

Several factors that are closely correlated with geographic location and ethnicity may impact the efficacy of ICI therapy (47). Firstly, the patterns of oncogene-driven mutations vary substantially between Asian and nonAsian countries. It is widely acknowledged that EGFR mutations are much more common in Asians, while KRAS mutations are more common in Western populations (47). About $47.9 \%$ of Asians carry EGFR mutation, while the incidence was about $15 \%$ in the Caucasian population. Conversely, the rate of KRAS mutation was higher in the Caucasian population (30\% vs. 7\%) (46). The gene mutations mentioned above are proven to be involved in the immunologic response (48). Many studies have demonstrated that clinical benefit of ICI could be observed in EGFR wild-type patients but not in EGFR mutationpositive NSCLC patients in comparison to docetaxel $(35,49-51)$. Furthermore, EGFR mutations might bring about a potentially higher hazard of hyper progression after the immunotherapy (52).

Aside from the wide divergence in genetic backgrounds, many factors may exert effects on the therapeutic benefit to patients from diverse geographic regions such as dietary habits, environmental pollution, tobacco and alcohol consumption, socioeconomic status, and others (53). Taking tobacco use for example, the amount of former/current smokers was higher in non-Asian population compared with Asian (54). It has been reported that ICI were more efficient in smoking NSCLC patients (16). Furthermore, certain viral infections have evident regional characteristics, such as the hepatitis B virus (HBV). Research showed that Asia comprised approximately $62 \%$ of worldwide HBV burden (55). Moreover, the number of Chinese patients with HBV exceeded 93 million, which is significantly higher than those in Europe and the United States (56). Whether HBV infection plays a key role in the efficacy of ICI is still unknown since those certain patients are usually excluded by most of the RCTs. More studies are warranted to explain this issue. More recently, works of literature have emerged that offer contradictory findings of the impact of antibiotic treatment on ICI therapy in different regions. According to Pinato et al. (57), exposure to broad-spectrum antibiotic therapy prior to ICI therapy is associated with worse treatment response and OS in patients of multicenter ICI therapy studies. This could potentially explain the disadvantage in outcomes among Asian subgroups who are more likely to be overprescribed antibiotics as well as access them illicitly and over-the-counter (58). However, there is a contrary outcome reported by Metges et al., who found survival advantages for French patients receiving antibiotics prior to the ICI therapy (59). More features regarding the molecular mechanism of regional differences and evaluation of the influence of antibiotics should be taken into account in future clinical trial design.

Several types of cancer, such as lung cancer and melanoma displayed a region-independent benefit from the ICI treatment, whereas other types of cancer such as head and neck cancer, prostate cancer and gastric or gastrooesophageal junction cancer showed little benefit or even failed to improve the survival data from the administration of ICI agents. These results reflect those of Teufel $\mathrm{et} \mathrm{al}$. (2019) (60), who also observed that patients with pancreatic cancer or hepatocellular carcinoma or head and neck squamous cell displayed resistance against ICI and could not benefit from ICI treatment. Distinguishing cancer cells as foreign is the necessary prerequisite to the induction of adaptive immune responses for tumors. High TMB and elevated neoantigen expression are foundational to antitumor immunity according to several reports $(17,61,62)$. This analysis adds to the body of findings indicating that tumor types characterized as poorly immunogenic are inherently less sensitive to immunotherapy.

When we assessed whether the setting line of ICI treatment impacted the risk of death among different geographic locations, the results of three were in line with each other. Reduced risk of death was identified when ICI agents were applied in first-line treatment compared with subsequent-line treatment regardless of region. The primary mechanism of ICI treatment is harnessing the immune system to fight malignancy $(17,63)$. Therefore, a functional immune system is essential for ICI to produce a marked effect, so ICI added to first-line treatment regimen is more likely to produce a better clinical outcome.

To our knowledge, this is the first assessment of regional differences in ICI treatment efficacy exclusive to Phase III trial data. However, this meta-analysis also has 
several shortcomings. Firstly, our meta-analysis is based on published data so no clinicopathological characteristics of individual patients are examined. This precludes the possibility of exploring potential associations between variables. Secondly, it is noteworthy that some subgroup analyses included few trials, which might reduce their statistical power. In addition, some RCTs of anti-PD-L1 inhibitors were not included due to the lack of survival data of designated region, which makes us unable to evaluate the regional differences of survival data. Consequently, our analysis should be interpreted cautiously considering the above concern. Furthermore, despite using the randomeffects model and conducting subgroup analyses, the heterogeneity among the included studies is still an issue that cannot be ignored. The origin of heterogeneity lies in the diversity of patient baseline characteristics, such as cancer type, PD-L1 expression level, ECOG, and other factors. In addition, ICI dosage could also account for the heterogeneity. Finally, the impact of regional variation should be assessed in terms of safety as well as clinical benefit. Accordingly, further meta-analysis from updated information will be required.

\section{Conclusions}

In conclusion, our meta-analysis indicates that ICI could significantly prolong patients' OS compared to control treatment in a region-independent fashion. However, the magnitude of benefit varies by geographic location. Asian patients experience inferior outcomes compared to Western patients. Notably, anti-PD-L1 therapies do not result in survival improvements in Asian patients. We recommend that more region-related characteristics should be taken into consideration in the design of clinical trials with ICI, such as exposure to antibiotic therapy, tobacco and alcohol consumption, socioeconomic status, and other factors. More detailed high-quality clinical studies are warranted to clarify the impact of geographic region on efficacy of ICI and explore the potential subgroups susceptible to specific ICI.

\section{Acknowledgments}

The authors thank all participants for their participation. The authors thank Nathaniel Weygant for his effort in revision of English and polishing.

Funding: The work was supported by Beijing Natural Science Foundation (7202051); Beijing Municipal Administration of Hospitals, Incubating Program (code: PX 2020016).

\section{Footnote}

Reporting Checklist: The authors have completed the PRISMA reporting checklist. Available at http://dx.doi. org/10.21037/tcr-20-1800

Conflicts of Interest: All authors have completed the ICMJE uniform disclosure form (available at http://dx.doi. org/10.21037/tcr-20-1800). The authors have no conflicts of interest to declare.

Ethical Statement: The authors are accountable for all aspects of the work in ensuring that questions related to the accuracy or integrity of any part of the work are appropriately investigated and resolved.

Open Access Statement: This is an Open Access article distributed in accordance with the Creative Commons Attribution-NonCommercial-NoDerivs 4.0 International License (CC BY-NC-ND 4.0), which permits the noncommercial replication and distribution of the article with the strict proviso that no changes or edits are made and the original work is properly cited (including links to both the formal publication through the relevant DOI and the license). See: https://creativecommons.org/licenses/by-nc-nd/4.0/.

\section{References}

1. Ribas A, Wolchok JD. Cancer immunotherapy using checkpoint blockade. Science 2018;359:1350-5.

2. Duan J, Cui L, Zhao X, et al. Use of Immunotherapy With Programmed Cell Death 1 vs Programmed Cell Death Ligand 1 Inhibitors in Patients With Cancer: A Systematic Review and Meta-analysis. JAMA Oncol 2020;6:375-84.

3. Vaddepally RK, Kharel P, Pandey R, et al. Review of indications of FDA-approved immune checkpoint inhibitors per NCCN guidelines with the level of evidence. Cancers (Basel) 2020;12:1-19.

4. McDermott D, Haanen J, Chen TT, et al. Efficacy and safety of ipilimumab in metastatic melanoma patients surviving more than 2 years following treatment in a phase III trial (MDX010-20). Ann Oncol 2013;24:2694-8.

5. Martins F, Sofiya L, Sykiotis GP, et al. Adverse effects of immune-checkpoint inhibitors: epidemiology, management and surveillance. Nat Rev Clin Oncol 2019;16:563-80.

6. Hellmann MD, Rizvi NA, Goldman JW, et al. Nivolumab plus ipilimumab as first-line treatment for advanced nonsmall-cell lung cancer (CheckMate 012): results of an open-label, phase 1, multicohort study. Lancet Oncol 
2017;18:31-41.

7. Hellmann MD, Ciuleanu T-E, Pluzanski A, et al. Nivolumab plus Ipilimumab in Lung Cancer with a High Tumor Mutational Burden. N Engl J Med 2018 378:2093-104.

8. Antonia SJ, López-Martin JA, Bendell J, et al. Nivolumab alone and nivolumab plus ipilimumab in recurrent smallcell lung cancer (CheckMate 032): a multicentre, openlabel, phase 1/2 trial. Lancet Oncol 2016;17:883-95.

9. Motzer RJ, Tannir NM, McDermott DF, et al. Nivolumab plus Ipilimumab versus Sunitinib in Advanced Renal-Cell Carcinoma. N Engl J Med 2018;378:1277-90.

10. Larkin J, Chiarion-Sileni V, Gonzalez R, et al. Combined nivolumab and ipilimumab or monotherapy in untreated Melanoma. N Engl J Med 2015;373:23-34.

11. Overman MJ, McDermott R, Leach JL, et al. Nivolumab in patients with metastatic DNA mismatch repair-deficient or microsatellite instability-high colorectal cancer (CheckMate 142): an open-label, multicentre, phase 2 study. Lancet Oncol 2017;18:1182-91.

12. Kenmotsu H, Tanigawara Y. Pharmacokinetics, dynamics and toxicity of docetaxel: Why the Japanese dose differs from the Western dose. Cancer Sci 2015;106:497-504.

13. Schmittel A, Sebastian M, Fischer von Weikersthal L, et al. A German multicenter, randomized phase III trial comparing irinotecan-carboplatin with etoposidecarboplatin as first-line therapy for extensive-disease smallcell lung cancer. Ann Oncol 2011;22:1798-804.

14. Wang E, Nickens DJ, Bello A, et al. Clinical implications of the pharmacokinetics of crizotinib in populations of patients with non-small cell lung cancer. Clin Cancer Res 2016;22:5722-8.

15. Borno H, George DJ, Schnipper LE, et al. All Men Are Created Equal: Addressing Disparities in Prostate Cancer Care. Am Soc Clin Oncol Educ Book 2019;39:302-308.

16. Li B, Huang X, Fu L. Impact of smoking on efficacy of PD-1/PD-L1 inhibitors in non-small cell lung cancer patients: a meta-analysis. Onco Targets Ther 2018;11:3691-6.

17. Fares CM, Van Allen EM, Drake CG, et al. Mechanisms of Resistance to Immune Checkpoint Blockade: Why Does Checkpoint Inhibitor Immunotherapy Not Work for All Patients? Am Soc Clin Oncol Educ Book 2019;39:147-64.

18. Moher D, Liberati A, Tetzlaff J, et al. Preferred reporting items for systematic reviews and meta-analyses: the PRISMA statement. PLoS Med 2009;6:e1000097.

19. Higgins JPT, Thomas J, Chandler J, et al. editors. Cochrane Handbook for Systematic Reviews of
Interventions version 6.0 (updated July 2019). Cochrane, 2019. Available online www.training.cochrane.org/ handbook

20. Higgins JPT, Altman DG, Gøtzsche PC, et al. The Cochrane Collaboration's tool for assessing risk of bias in randomised trials. BMJ 2011;343:d5928.

21. Begg CB, Mazumdar M. Operating Characteristics of a Rank Correlation Test for Publication Bias. Biometrics 1994;50:1088-101.

22. Egger M, Smith GD, Schneider M, et al. Bias in metaanalysis detected by a simple, graphical test. BMJ. 1997;315:629-34.

23. Brahmer J, Reckamp KL, Baas P, et al. Nivolumab versus Docetaxel in Advanced Squamous-Cell Non-Small-Cell Lung Cancer. N Engl J Med 2015;373:123-35.

24. Borghaei H, Paz-Ares L, Horn L, et al. Nivolumab versus Docetaxel in Advanced Nonsquamous Non-Small-Cell Lung Cancer. N Engl J Med 2015;373:1627-39.

25. Motzer RJ, Escudier B, McDermott DF, et al. Nivolumab versus Everolimus in Advanced Renal-Cell Carcinoma. N Engl J Med 2015;373:1803-13.

26. Ferris RL, Blumenschein G, Fayette J, et al. Nivolumab for Recurrent Squamous-Cell Carcinoma of the Head and Neck. N Engl J Med 2016;375:1856-67.

27. Kang YK, Boku N, Satoh T, et al. Nivolumab in patients with advanced gastric or gastro-oesophageal junction cancer refractory to, or intolerant of, at least two previous chemotherapy regimens (ONO-4538-12, ATTRACTION-2): a randomised, double-blind, placebocontrolled, phase 3 trial. Lancet 2017;390:2461-71.

28. Shitara K, Özgüroğlu M, Bang YJ, et al. Pembrolizumab versus paclitaxel for previously treated, advanced gastric or gastro-oesophageal junction cancer (KEYNOTE-061): a randomised, open-label, controlled, phase 3 trial. Lancet 2018;392:123-33.

29. Bang YJ, Ruiz EY, Van Cutsem E, et al. Phase III, randomised trial of avelumab versus physician's choice of chemotherapy as third-line treatment of patients with advanced gastric or gastro-oesophageal junction cancer: primary analysis of JAVELIN Gastric 300. Ann Oncol 2018;29:2052-60.

30. Robert C, Schachter J, Long GV, et al. Pembrolizumab versus Ipilimumab in Advanced Melanoma. N Engl J Med 2015;372:2521-32.

31. Larkin J, Chiarion-Sileni V, Gonzalez R, et al. Five-Year Survival with Combined Nivolumab and Ipilimumab in Advanced Melanoma. N Engl J Med 2019;381:1535-46.

32. Cohen EEW, Soulières D, Le Tourneau C, et al. 
Pembrolizumab versus methotrexate, docetaxel, or cetuximab for recurrent or metastatic head-and-neck squamous cell carcinoma (KEYNOTE-040): a randomised, open-label, phase 3 study. Lancet 2019;393:156-67.

33. Kwon ED, Drake CG, Scher HI, et al. Ipilimumab versus placebo after radiotherapy in patients with metastatic castration-resistant prostate cancer that had progressed after docetaxel chemotherapy (CA184-043): a multicentre, randomised, double-blind, phase 3 trial. Lancet Oncol 2014;15:700-12.

34. Antonia SJ, Villegas A, Daniel D, et al. Overall Survival with Durvalumab after Chemoradiotherapy in Stage III NSCLC. N Engl J Med 2018;379:2342-50.

35. Fehrenbacher L, von Pawel J, Park K, et al. Updated Efficacy Analysis Including Secondary Population Results for OAK: A Randomized Phase III Study of Atezolizumab versus Docetaxel in Patients with Previously Treated Advanced Non-Small Cell Lung Cancer. J Thorac Oncol 2018;13:1156-70.

36. Reck M, Rodríguez-Abreu D, Robinson AG, et al. Updated Analysis of KEYNOTE-024: Pembrolizumab Versus Platinum-Based Chemotherapy for Advanced NonSmall-Cell Lung Cancer With PD-L1 Tumor Proportion Score of 50\% or Greater. J Clin Oncol 2019;37:537-46.

37. Mok TSK, Wu YL, Kudaba I, et al. Pembrolizumab versus chemotherapy for previously untreated, PD-L1expressing, locally advanced or metastatic non-small-cell lung cancer (KEYNOTE-042): a randomised, open-label, controlled, phase 3 trial. Lancet 2019;393:1819-30.

38. Paz-Ares L, Luft A, Vicente D, et al. Pembrolizumab plus Chemotherapy for Squamous Non-Small-Cell Lung Cancer. N Engl J Med 2018;379:2040-51.

39. Paz-Ares L, Dvorkin M, Chen Y, et al. Durvalumab plus platinum-etoposide versus platinum-etoposide in firstline treatment of extensive-stage small-cell lung cancer (CASPIAN): a randomised, controlled, open-label, phase 3 trial. Lancet 2019;394:1929-39.

40. Wang Z, Zhang B, Zhang C, et al. Effect of region on the Outcome of Patients Receiving PD-1/PD-L1 Inhibitors for Advanced Cancer. Int Immunopharmacol 2019;74:105709.

41. Chen L, Han X. Anti-PD-1/PD-L1 therapy of human cancer: past, present, and future. J Clin Invest 2015;125:3384-91.

42. Yearley JH, Gibson C, Yu N, et al. PD-L2 Expression in Human Tumors: Relevance to Anti-PD-1 Therapy in Cancer. Clin Cancer Res 2017;23:3158-67.

43. George S, Papanicolau-Sengos A, Lenzo FL, et al. PD-L2 amplification and durable disease stabilization in patient with urothelial carcinoma receiving pembrolizumab. Oncoimmunology 2018;7:e1460298.

44. Ramamoorthy A, Pacanowski MA, Bull J, et al. Racial/ ethnic differences in drug disposition and response: Review of recently approved drugs. Clin Pharmacol Ther 2015;97:263-73.

45. Soo RA, Loh M, Mok TS, et al. Ethnic differences in survival outcome in patients with advanced stage non-small cell lung cancer: Results of a meta-analysis of randomized controlled trials. J Thorac Oncol 2011;6:1030-8.

46. Dearden S, Stevens J, Wu YL, et al. Mutation incidence and coincidence in non small-cell lung cancer: Metaanalyses by ethnicity and histology (mutMap). Ann Oncol 2013;24:2371-6.

47. Peng L, Wu YL. Immunotherapy in the Asiatic population: Any differences from Caucasian population? J Thorac Dis 2018;10:S1482-93.

48. Tam IYS, Chung LP, Suen WS, et al. Distinct epidermal growth factor receptor and KRAS mutation patterns in non-small cell lung cancer patients with different tobacco exposure and clinicopathologic features. Clin Cancer Res 2006;12:1647-53.

49. Antonia SJ, Villegas A, Daniel D, et al. Durvalumab after chemoradiotherapy in stage III non-small-cell lung cancer. N Engl J Med 2017;377:1919-29.

50. Oxnard GR, Yang JCH, Yu H, et al. TATTON: a multi-arm, phase Ib trial of osimertinib combined with selumetinib, savolitinib, or durvalumab in EGFR-mutant lung cancer. Ann Oncol 2020;31:507-16.

51. Herbst RS, Baas P, Kim DW, et al. Pembrolizumab versus docetaxel for previously treated, PD-L1-positive, advanced non-small-cell lung cancer (KEYNOTE-010): a randomised controlled trial. Lancet 2016;387:1540-50.

52. Kato S, Goodman A, Walavalkar V, et al. Hyperprogressors after Immunotherapy: Analysis of Genomic Alterations Associated with Accelerated Growth Rate. Clin Cancer Res 2017;23:4242-50.

53. Hu J. Any Difference on Efficacy and Toxicity Between East and West? J Thorac Oncol 2019;14:S125.

54. Qian J, Nie W, Lu J, et al. Racial differences in characteristics and prognoses between Asian and white patients with nonsmall cell lung cancer receiving atezolizumab: An ancillary analysis of the POPLAR and OAK studies. Int J Cancer 2020;146:3124-33.

55. Degenhardt L, Charlson F, Stanaway J, et al. Estimating the burden of disease attributable to injecting drug use as a risk factor for $\mathrm{HIV}$, hepatitis $\mathrm{C}$, and hepatitis B: findings 
from the Global Burden of Disease Study 2013. Lancet Infect Dis 2016;16:1385-98.

56. Wang FS, Fan JG, Zhang Z, et al. The global burden of liver disease: The major impact of China. Hepatology 2014;60:2099-108.

57. Pinato DJ, Howlett S, Ottaviani D, et al. Association of Prior Antibiotic Treatment With Survival and Response to Immune Checkpoint Inhibitor Therapy in Patients With Cancer. JAMA Oncol 2019;5:1774-8.

58. O'Neill J. Antimicrobial Resistance: Tackling a crisis for the health and wealth of nations. the Review on Antimicrobial Resistance. 2016.

59. Metges JP, Michaud E, Deniel Lagadec D, et al. Impact of anti-infectious and corticosteroids on immunotherapy: Nivolumab and pembrolizumab follow-up in a French study. Ann Oncol 2018;36:e15157.

Cite this article as: Li M, Yao J, Zhang H, Ge Y, An G. Geographic heterogeneity in the outcomes of patients receiving immune checkpoint inhibitors for advanced solid tumors: a meta-analysis. Transl Cancer Res 2021;10(1):310-326. doi: 10.21037/tcr-20-1800
60. Teufel A, Zhan T, Härtel N, et al. Management of immune related adverse events induced by immune checkpoint inhibition. Cancer Lett 2019;456:80-7.

61. Rizvi NA, Hellmann MD, Snyder A, et al. Cancer immunology. Mutational landscape determines sensitivity to PD-1 blockade in non-small cell lung cancer. Science 2015;348:124-8.

62. Rizvi H, Sanchez-Vega F, La K, et al. Molecular Determinants of Response to Anti-Programmed Cell Death (PD)-1 and Anti-Programmed Death-Ligand 1 (PD-L1) Blockade in Patients With Non-Small-Cell Lung Cancer Profiled With Targeted Next-Generation Sequencing. J Clin Oncol 2018;36:633-41.

63. Wei SC, Duffy CR, Allison JP. Fundamental Mechanisms of Immune Checkpoint Blockade Therapy. Cancer Discov 2018;8:1069-86. 


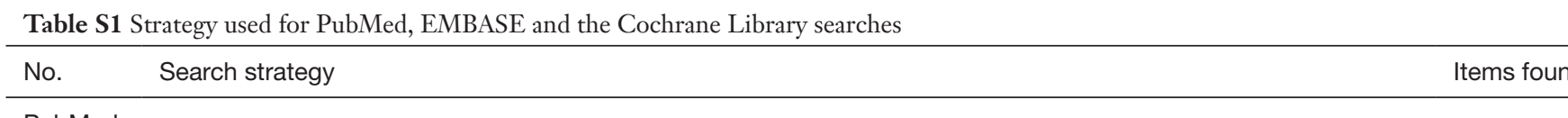

Noopasansminess Tremss

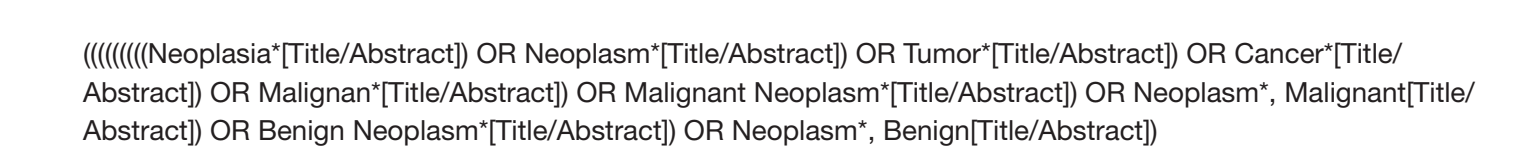

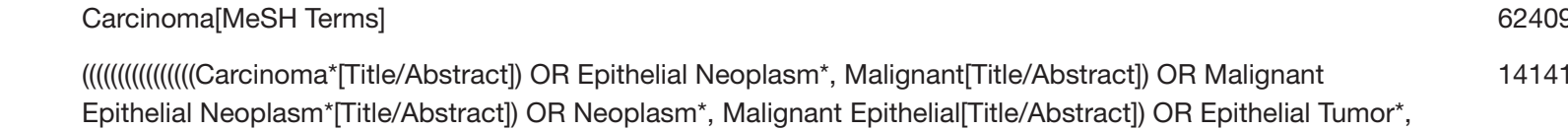

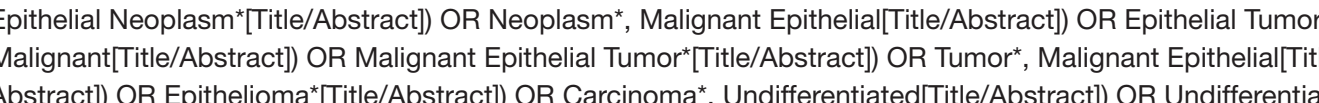

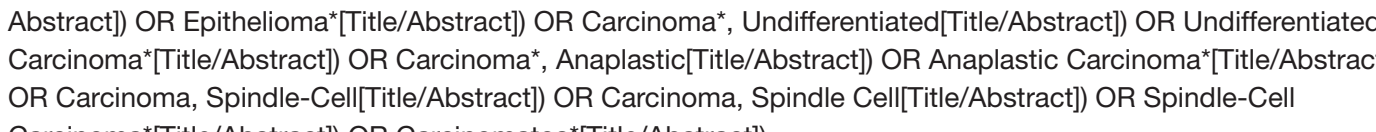

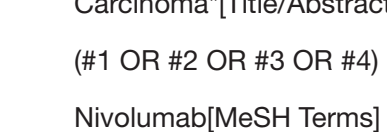

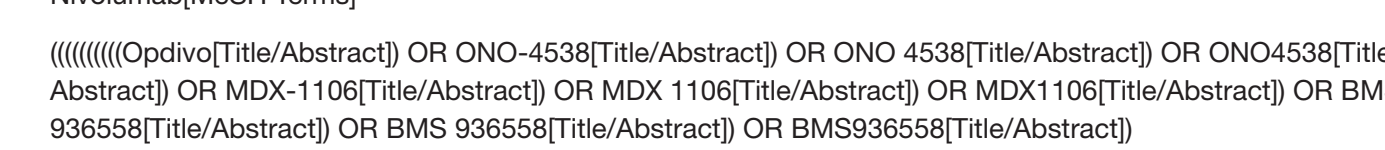

"8.

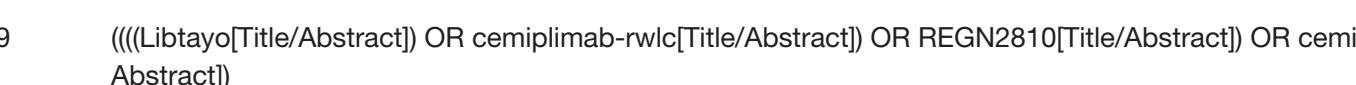

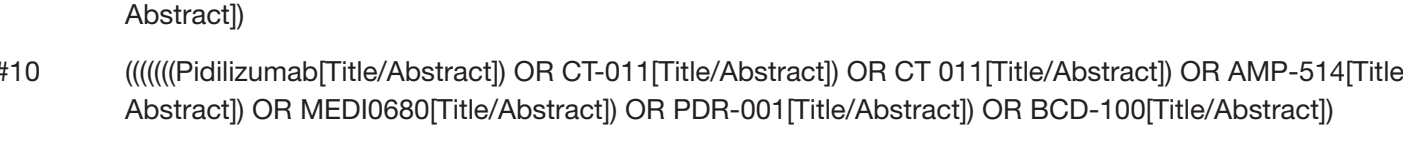

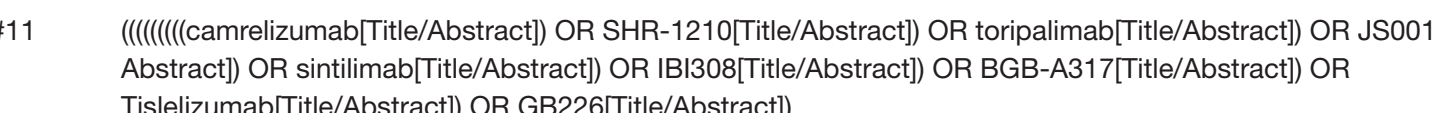

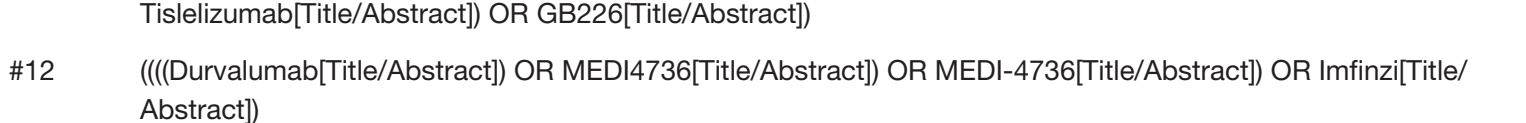

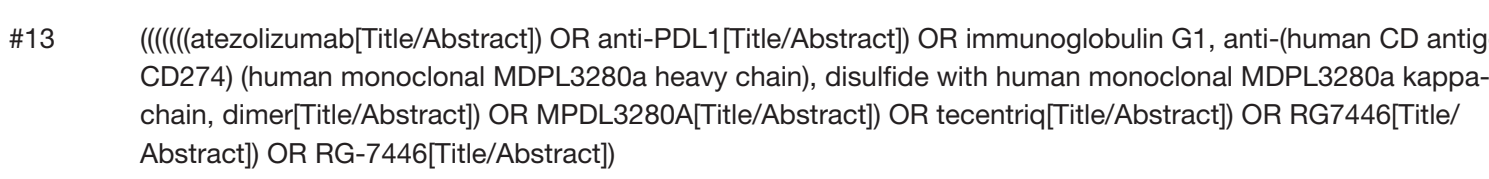

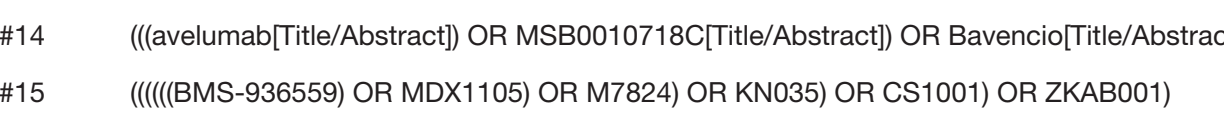

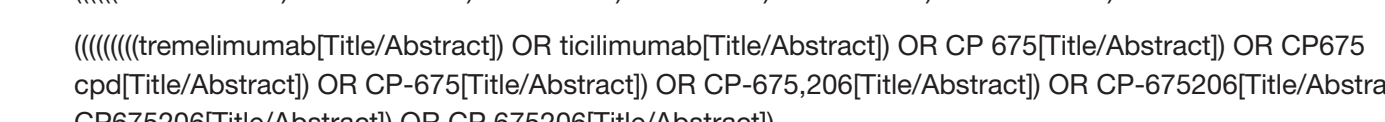

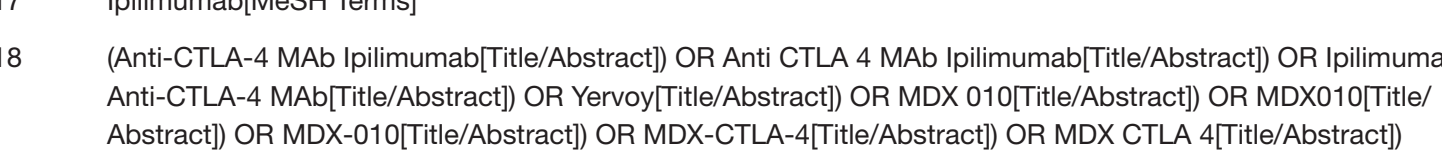

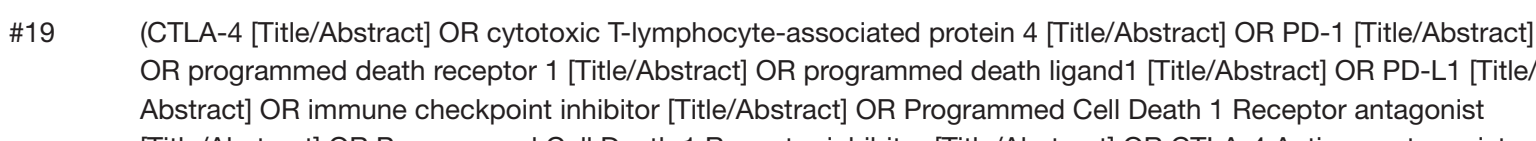

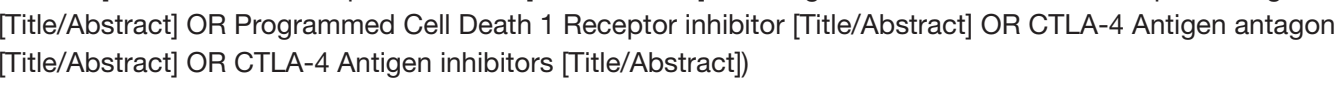

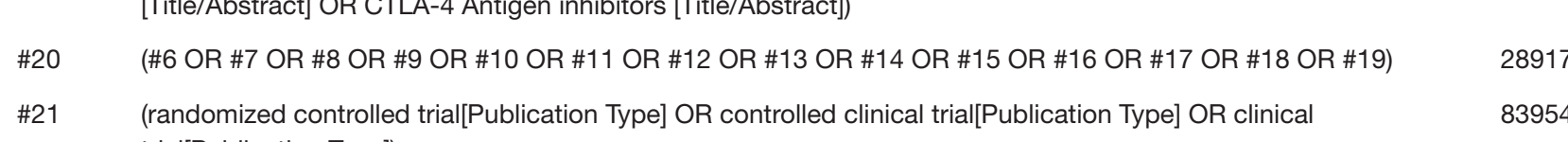

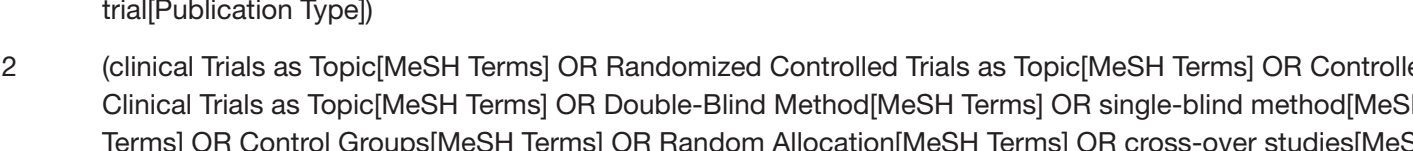

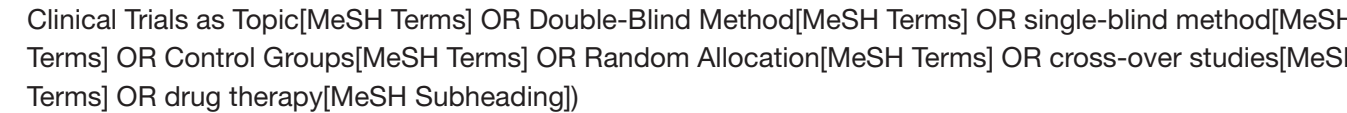

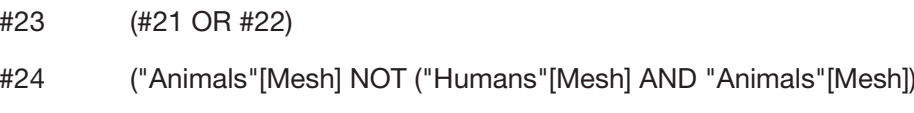

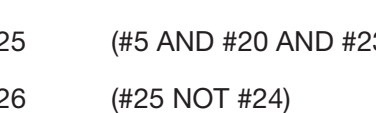

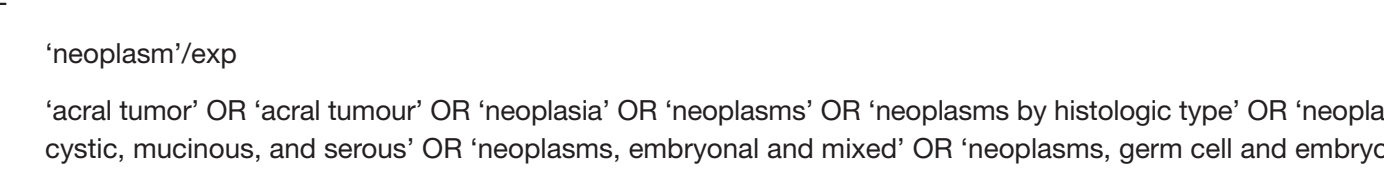

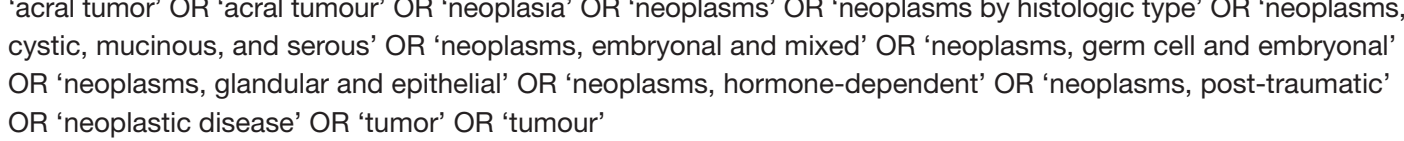

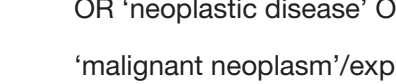

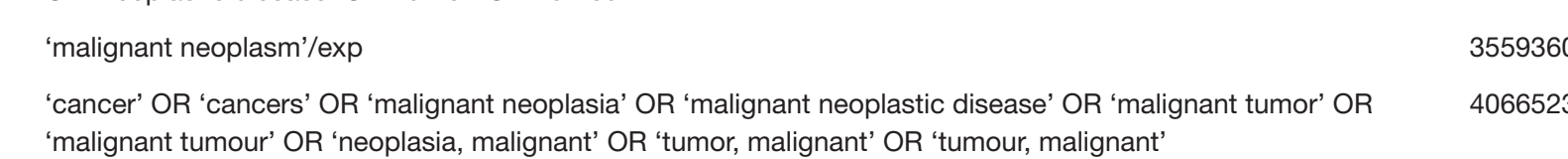

120270
832

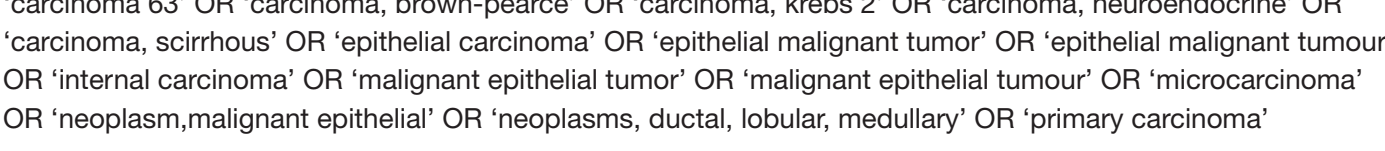

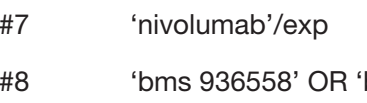

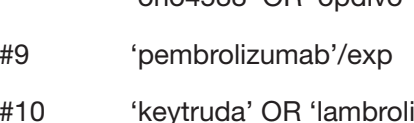

1 'cempipimab'/ext

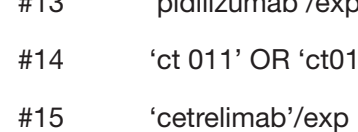

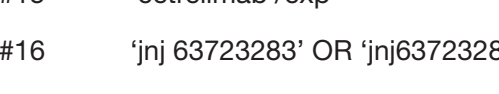

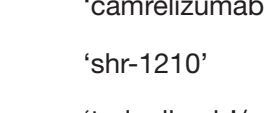

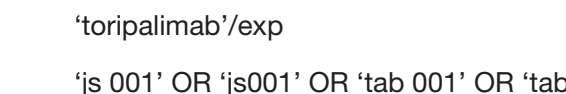

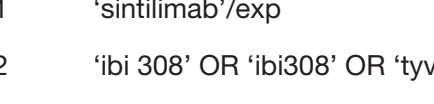

Instilumab exp

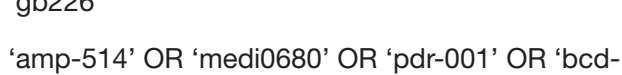

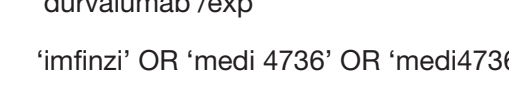

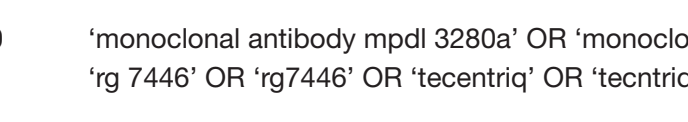

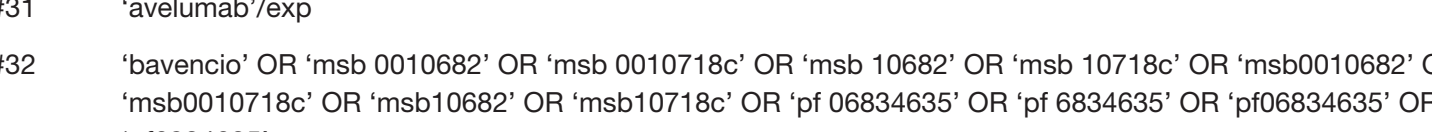

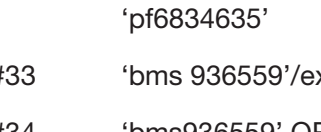

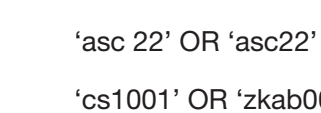

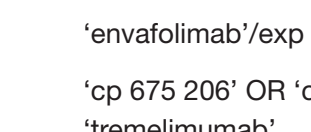

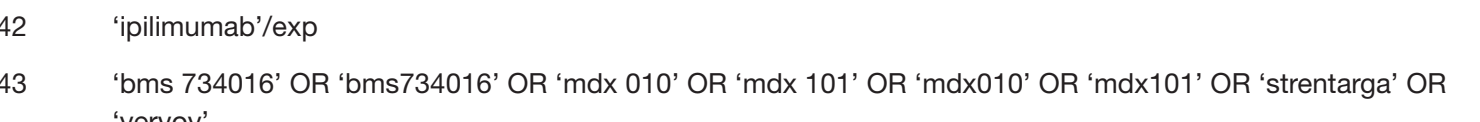

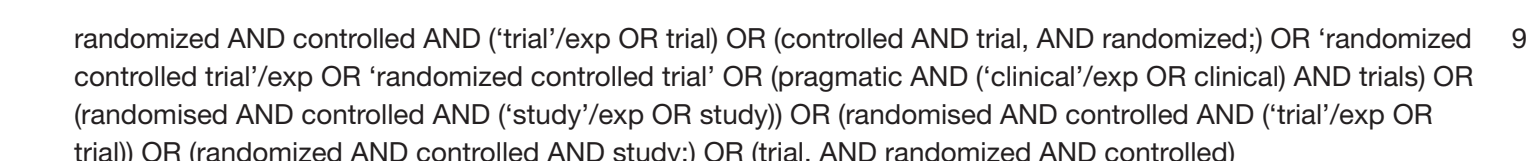

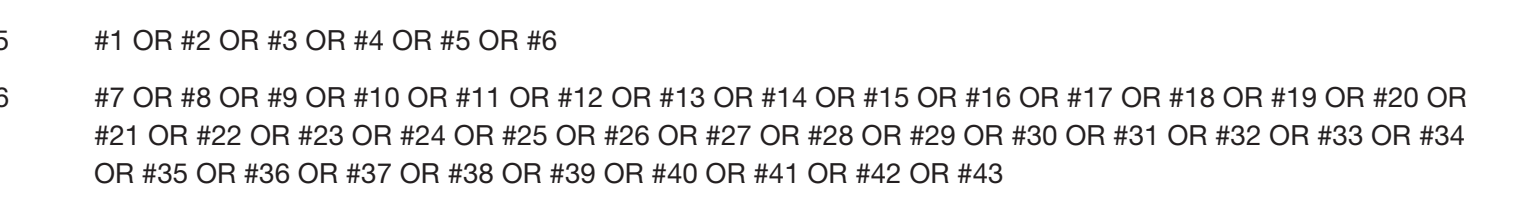

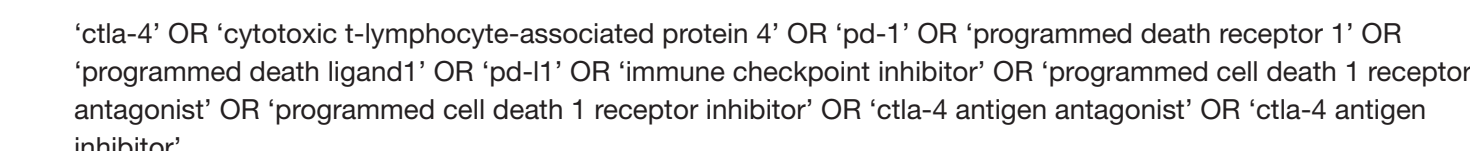

448
49

Mest descripor: Noophasssus explode al trees

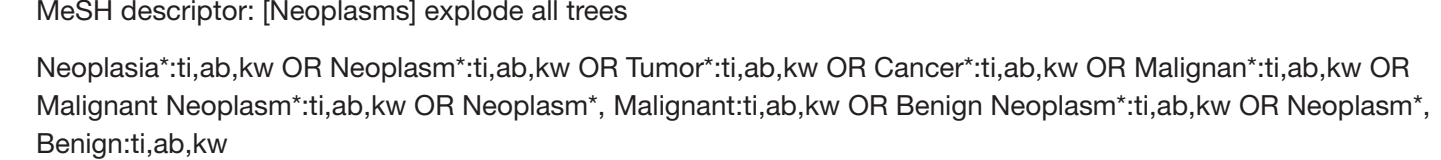
mest desine

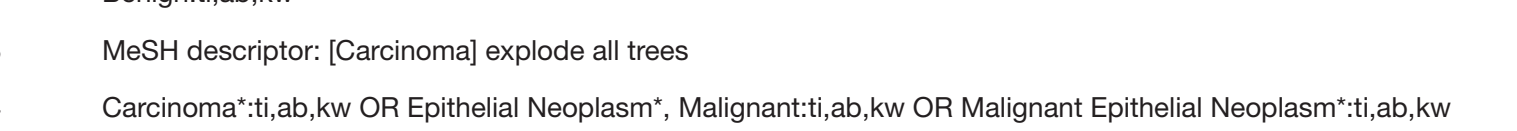

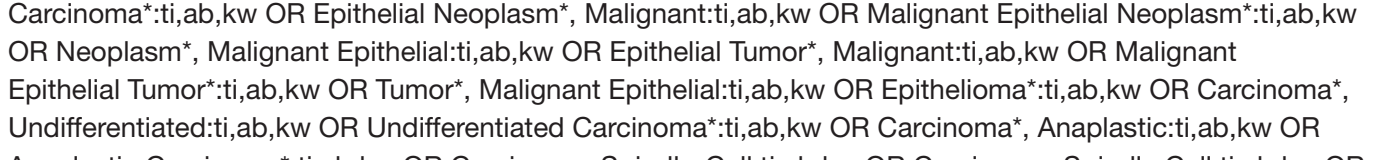

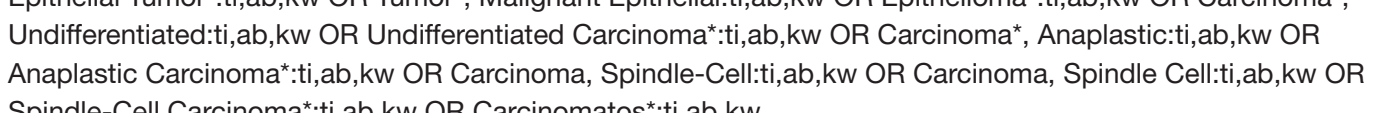

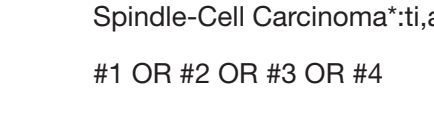

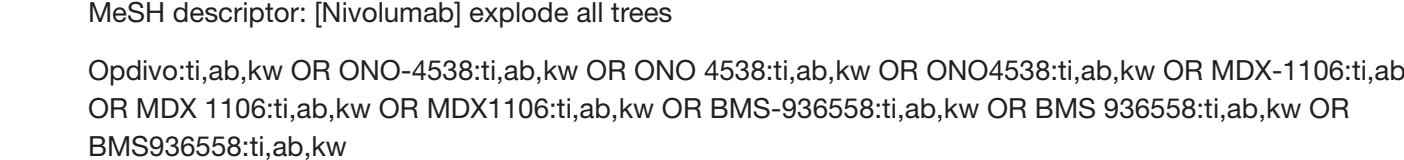

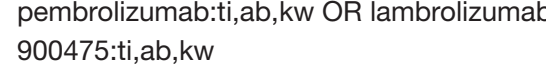

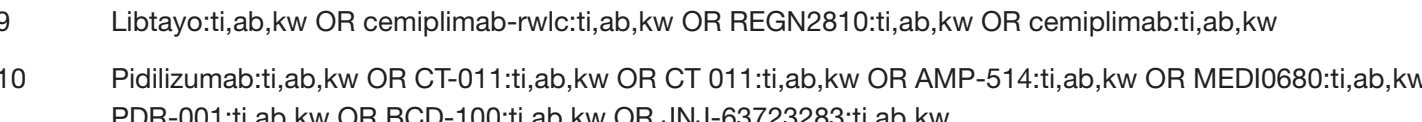

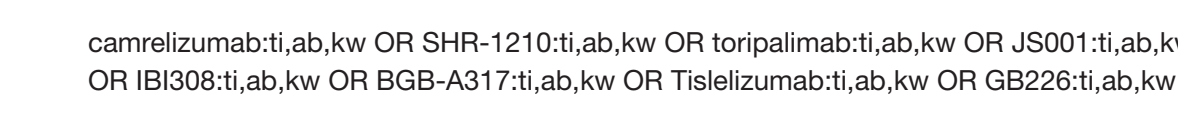

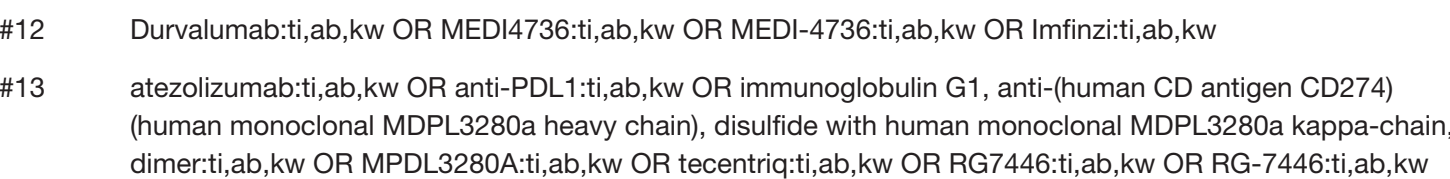

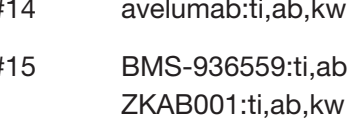

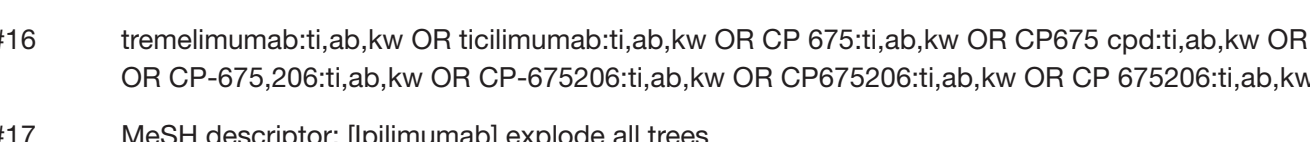

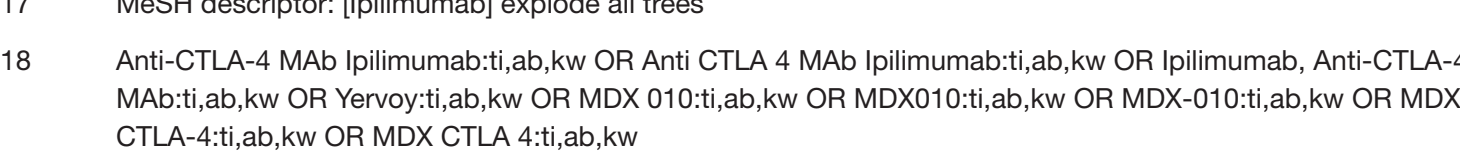

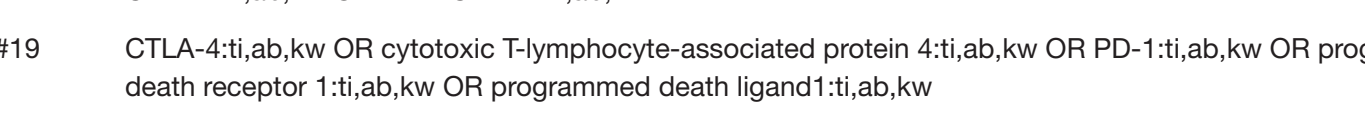

20
20

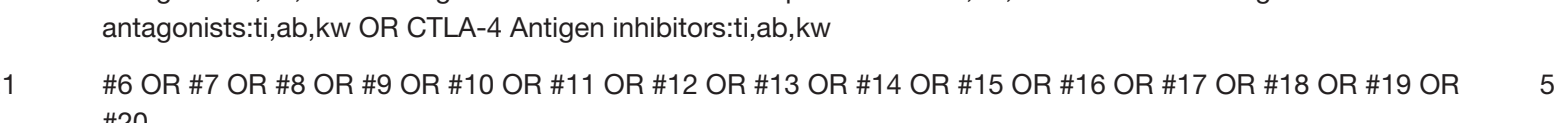

"\$5 AND 


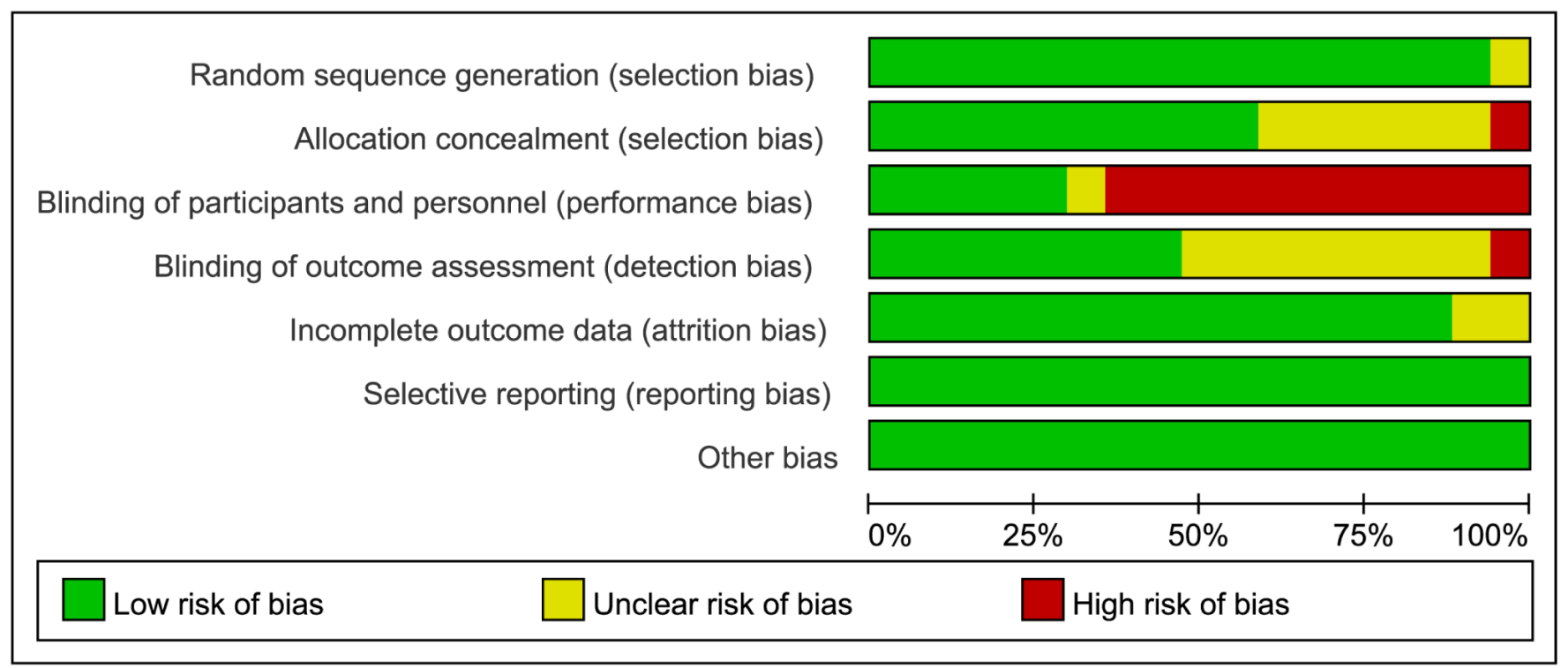

Figure S1 Risk of bias graph: Review authors' judgments about each risk of bias item presented as percentages across all included studies. 


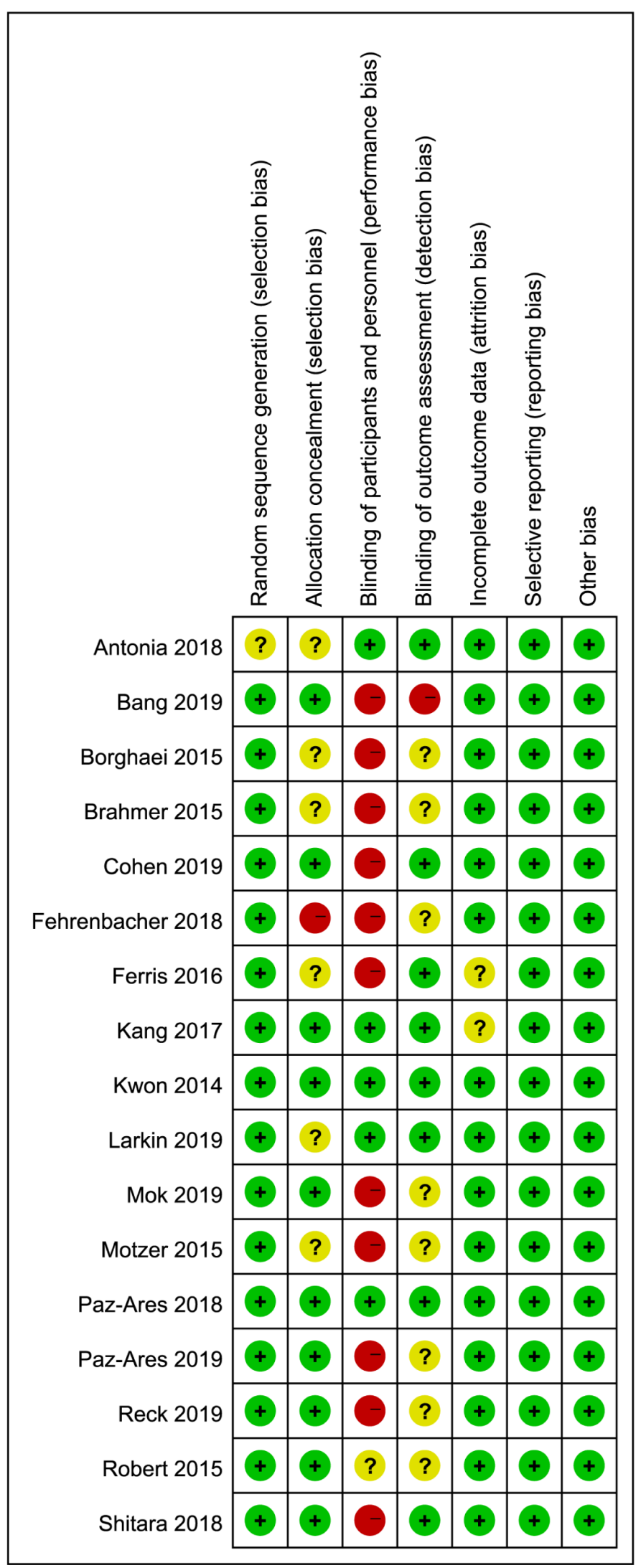

Figure S2 Risk of bias summary: Review authors' judgments about each risk of bias item for each included study. 


\begin{tabular}{|c|c|c|c|c|c|c|c|c|}
\hline \multirow{2}{*}{ A study or Subgroup } & log[Hazard Ratio] & \multicolumn{3}{|c|}{$\begin{array}{ll} & \text { Hazard Ratio } \\
\text { SE Weight } & \text { IV. Random. 95\% CI }\end{array}$} & \multicolumn{4}{|c|}{ Hazard Ratio } \\
\hline & & \multicolumn{3}{|c|}{ SE Weight IV, Random, $95 \% \mathrm{Cl}$} & & & \multirow{11}{*}{-} & \\
\hline Borghaei 2015 & -0.6539 & 0.1736 & $5.6 \%$ & $0.52[0.37,0.73]$ & & - & & \\
\hline Brahmer 2015 & -0.5276 & 0.2521 & $3.5 \%$ & $0.59[0.36,0.97]$ & & $\longrightarrow$ & & \\
\hline Cohen 2019 & 0.239 & 0.2232 & $4.1 \%$ & $1.27[0.82,1.97]$ & & & & \\
\hline Ferris 2016 & -0.5978 & 0.2162 & $4.3 \%$ & $0.55[0.36,0.84]$ & & - & & \\
\hline Larkin 2019 & -0.3285 & 0.2176 & $4.3 \%$ & $0.72[0.47,1.10]$ & & 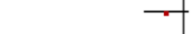 & & \\
\hline Larkin 2019 & -0.844 & 0.2374 & $3.8 \%$ & $0.43[0.27,0.68]$ & & - & & \\
\hline Motzer 2015 & -0.4155 & 0.1625 & $6.0 \%$ & $0.66[0.48,0.91]$ & & - & & \\
\hline Robert 2015 & -0.5978 & 0.4675 & $1.3 \%$ & $0.55[0.22,1.38]$ & & - & & \\
\hline Robert 2015 & -0.7133 & 0.4834 & $1.2 \%$ & $0.49[0.19,1.26]$ & & & & \\
\hline Subtotal $(95 \% \mathrm{Cl})$ & & & $34.0 \%$ & $0.63[0.51,0.78]$ & & 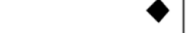 & & \\
\hline \multicolumn{9}{|c|}{ Heterogeneity: $\mathrm{Tau}^{2}=0.05 ; \mathrm{Chi}^{2}=14.95, \mathrm{df}=8(P=0.06) ; \mathrm{I}^{2}=46 \%$} \\
\hline \multicolumn{9}{|c|}{ Test for overall effect: $Z=4.30(P<0.0001)$} \\
\hline \multicolumn{9}{|l|}{ 9.1.2 Europe } \\
\hline Borghaei 2015 & -0.2107 & 0.1447 & $6.7 \%$ & $0.81[0.61,1.08]$ & & - & & \\
\hline Brahmer 2015 & -0.6931 & 0.1968 & $4.8 \%$ & $0.50[0.34,0.74]$ & & 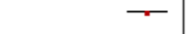 & & \\
\hline Cohen 2019 & -0.3857 & 0.1369 & $7.0 \%$ & $0.68[0.52,0.89]$ & & - & & \\
\hline Ferris 2016 & -0.0943 & 0.1958 & $4.9 \%$ & $0.91[0.62,1.34]$ & & - & & \\
\hline Larkin 2019 & -0.6733 & 0.1369 & $7.0 \%$ & $0.51[0.39,0.67]$ & & - & & \\
\hline Larkin 2019 & -0.5276 & 0.127 & $7.4 \%$ & $0.59[0.46,0.76]$ & & - & & \\
\hline Motzer 2015 & -0.1508 & 0.1588 & $6.1 \%$ & $0.86[0.63,1.17]$ & & & & \\
\hline Subtotal $(95 \% \mathrm{Cl})$ & & & $43.9 \%$ & $0.67[0.57,0.80]$ & & 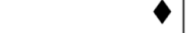 & & \\
\hline \multicolumn{9}{|c|}{ Heterogeneity: $\mathrm{Tau}^{2}=0.03 ; \mathrm{Chi}^{2}=13.82, \mathrm{df}=6(P=0.03) ;\left.\right|^{2}=57 \%$} \\
\hline \multicolumn{9}{|c|}{ Test for overall effect: $Z=4.52(P<0.00001)$} \\
\hline 9.1.3 Asia & & & & & & & & \\
\hline Kang 2017 & -0.462 & 0.1078 & $8.3 \%$ & $0.63[0.51,0.78]$ & & - & & \\
\hline Mok 2019 & -0.2357 & 0.1489 & $6.5 \%$ & $0.79[0.59,1.06]$ & & - & & \\
\hline Paz-Ares 2018 & -0.821 & 0.3537 & $2.1 \%$ & $0.44[0.22,0.88]$ & & - & & \\
\hline Reck 2019 & -1.0498 & 0.5462 & $1.0 \%$ & $0.35[0.12,1.02]$ & & 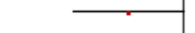 & & \\
\hline Shitara 2018 & -0.1054 & 0.2154 & $4.3 \%$ & $0.90[0.59,1.37]$ & & & & \\
\hline Subtotal $(95 \% \mathrm{Cl})$ & & & $22.2 \%$ & $0.68[0.55,0.85]$ & & $\bullet$ & & \\
\hline Heterogeneity: $\mathrm{Tau}^{2}=$ & $0.02 ; \mathrm{Chi}^{2}=6.20, \mathrm{df}=$ & $=4(P=$ & .18); $1^{2}=3$ & & & & & \\
\hline Test for overall effect & $Z=3.38(P=0.0007)$ & & & & & & & \\
\hline Total $(95 \% \mathrm{Cl})$ & & & $100.0 \%$ & $0.66[0.59,0.73]$ & & 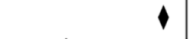 & & \\
\hline Heterogeneity: Tau $^{2}=$ & $0.03 ; \mathrm{Chi}^{2}=35.56, \mathrm{df}$ & $f=20(P$ & $=0.02) ; 1^{2}$ & $=44 \%$ & 0.01 & 0.1 & 10 & 100 \\
\hline Test for overall effect & $Z=7.48(P<0.00001$ & & & & $0.07 \mathrm{Fa}-\mathrm{a}$ & avours intervention & Favours control & \\
\hline Test for subaroun diff & rences: $\mathrm{Chi}^{2}=0.34 . \mathrm{d}$ & $d f=2(P$ & $=0.84) .1^{2}$ & $=0 \%$ & & & & \\
\hline & & & & Hazard Ratio & & Hazard & d Ratio & \\
\hline B study or Subgroup & log[Hazard Ratio] & SE & Weight & IV. Random. $95 \% \mathrm{Cl}$ & & IV. Randor & $\mathrm{m}, 95 \% \mathrm{Cl}$ & \\
\hline 9.2.1 North America & & & & & & & & \\
\hline Fehrenbacher 2018 & -0.3285 & 0.1282 & $12.2 \%$ & $0.72[0.56,0.93]$ & & $=$ & & \\
\hline $\begin{array}{l}\text { Fehrenbacher } 2018 \\
\text { Subtotal }(95 \% \mathrm{Cl})\end{array}$ & -0.4943 & 0.1552 & $\begin{array}{r}8.3 \% \\
20.5 \%\end{array}$ & $\begin{array}{l}0.61[0.45,0.83] \\
0.67[0.55,0.82]\end{array}$ & & $\bar{\varphi}$ & & \\
\hline Heterogeneity: Tau $^{2}=$ & $0.00 ; \mathrm{Chi}^{2}=0.68, \mathrm{df}=$ & $=1(P=$ & $.41) ; 1^{2}=0$ & & & & & \\
\hline Test for overall effect & $Z=4.00(P<0.0001)$ & & & & & & & \\
\hline 9.2.2 Europe & & & & & & & & \\
\hline Antonia 2018 & -0.1508 & 0.1752 & $6.5 \%$ & $0.86[0.61,1.21]$ & & - & & \\
\hline Fehrenbacher 2018 & -0.2357 & 0.0917 & $23.9 \%$ & $0.79[0.66,0.95]$ & & - & & \\
\hline Fehrenbacher 2018 & -0.1985 & 0.1107 & $16.4 \%$ & $0.82[0.66,1.02]$ & & - & & \\
\hline Paz-Ares 2019 & -0.3285 & 0.1282 & $12.2 \%$ & $0.72[0.56,0.93]$ & & $=$ & & \\
\hline Subtotal $(95 \% \mathrm{Cl})$ & & & $59.0 \%$ & $0.79[0.71,0.89]$ & & 1 & & \\
\hline Heterogeneity: $\mathrm{Tau}^{2}=$ & $0.00 ; \mathrm{Chi}^{2}=0.87, \mathrm{df}=$ & $=3(P=$ & $1.83) ; 1^{2}=0$ & & & & & \\
\hline Test for overall effect & $Z=4.03(P<0.0001)$ & & & & & & & \\
\hline 9.2.3 Asia & & & & & & & & \\
\hline Antonia 2018 & -0.4005 & 0.2506 & $3.2 \%$ & $0.67[0.41,1.09]$ & & ? & & \\
\hline Bang 2019 & 0.2311 & 0.2382 & $3.5 \%$ & $1.26[0.79,2.01]$ & & & & \\
\hline Fehrenbacher 2018 & -0.1393 & 0.1728 & $6.7 \%$ & $0.87[0.62,1.22]$ & & - & & \\
\hline Fehrenbacher 2018 & -0.2877 & 0.1968 & $5.2 \%$ & $0.75[0.51,1.10]$ & & $\rightarrow$ & & \\
\hline Paz-Ares 2019 & -0.1985 & 0.3294 & $1.8 \%$ & $0.82[0.43,1.56]$ & & i & & \\
\hline Subtotal $(95 \% \mathrm{Cl})$ & & & $20.5 \%$ & $0.85[0.70,1.04]$ & & & & \\
\hline Heterogeneity: $\mathrm{Tau}^{2}=$ & $0.00 ; \mathrm{Chi}^{2}=4.07, \mathrm{df}=$ & $=4(\mathrm{P}=$ & 1.40); $1^{2}=2$ & & & & & \\
\hline Test for overall effect & $Z=1.59(P=0.11)$ & & & & & & & \\
\hline Total $(95 \% \mathrm{Cl})$ & & & $100.0 \%$ & $0.78[0.71,0.85]$ & & 1 & & \\
\hline Heterogeneity: $\mathrm{Tau}^{2}=$ & $0.00 ; \mathrm{Chi}^{2}=8.70, \mathrm{df}=$ & $=10(P$ & $0.56) ; 1^{2}=$ & & & & & 100 \\
\hline $\begin{array}{l}\text { Test for overall effect } \\
\text { Test for subaroun diff }\end{array}$ & $Z=5.64(P<0.00001$ & & & & & urs intervention & Favours contr & \\
\hline
\end{tabular}

Figure S3 Pooled hazard ratios and 95\% CI for overall survival in patients treated with anti-PD-1 inhibitors (A) or anti-PD-L1 inhibitors (B) according to class of ICI. 


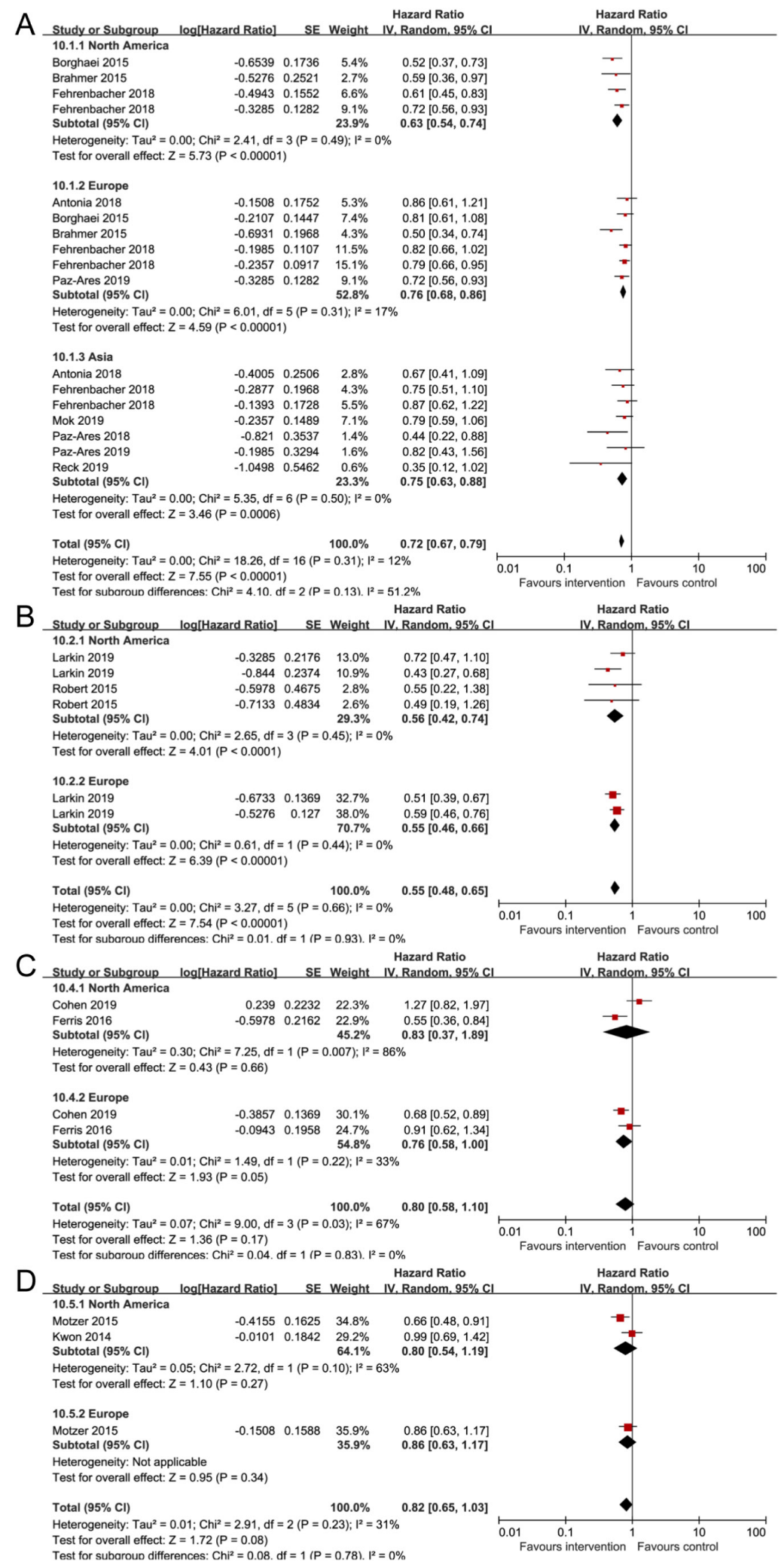

Figure S4 Pooled hazard ratios and 95\% CI for overall survival in lung cancer (A), melanoma (B), head and neck cancer (C), and other cancers (D) according to cancer type. 


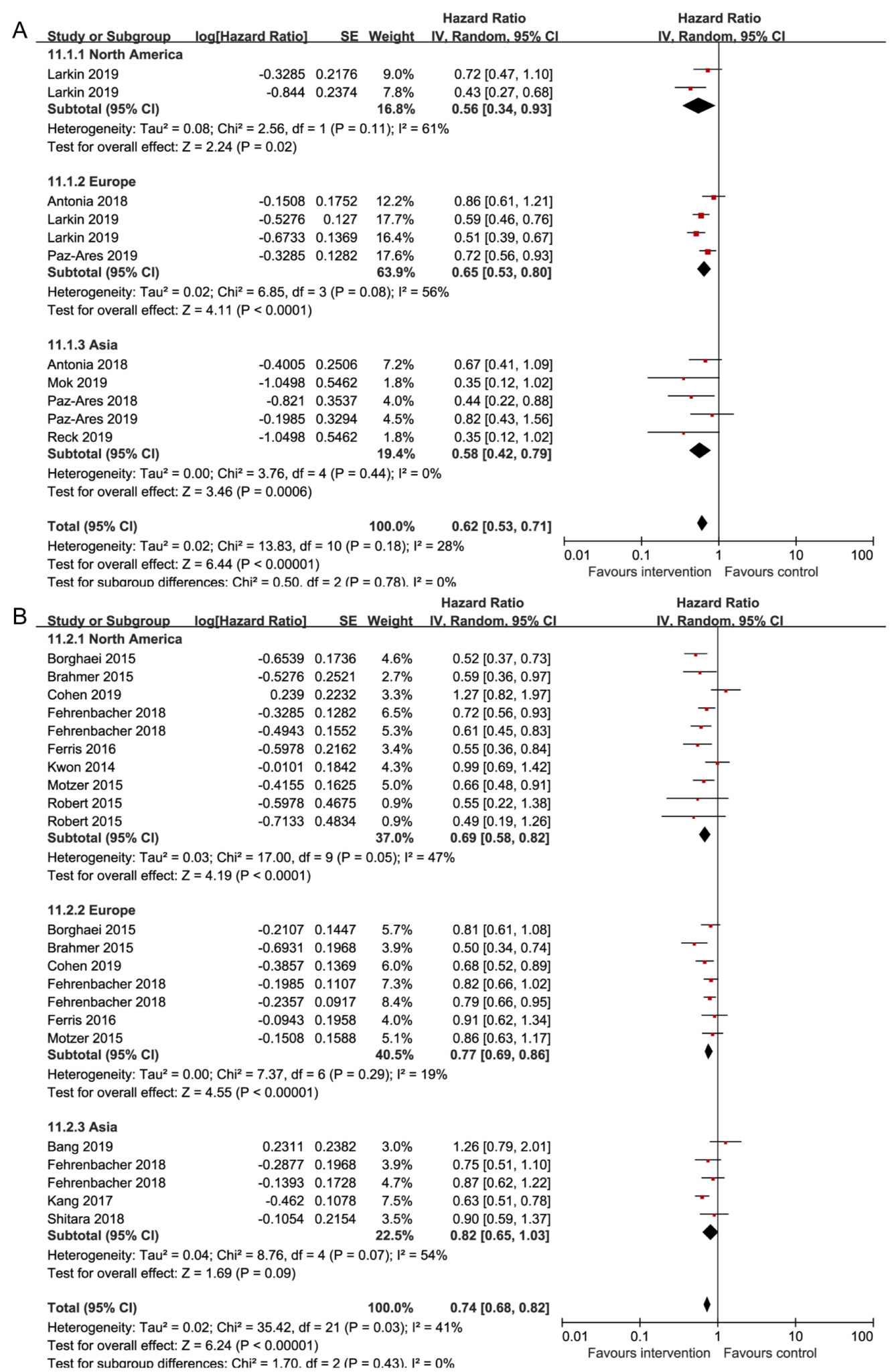

Figure S5 Pooled hazard ratios and 95\% CI for overall survival in first-line (A) or subsequent line (B) according to the setting line of ICI treatment. 


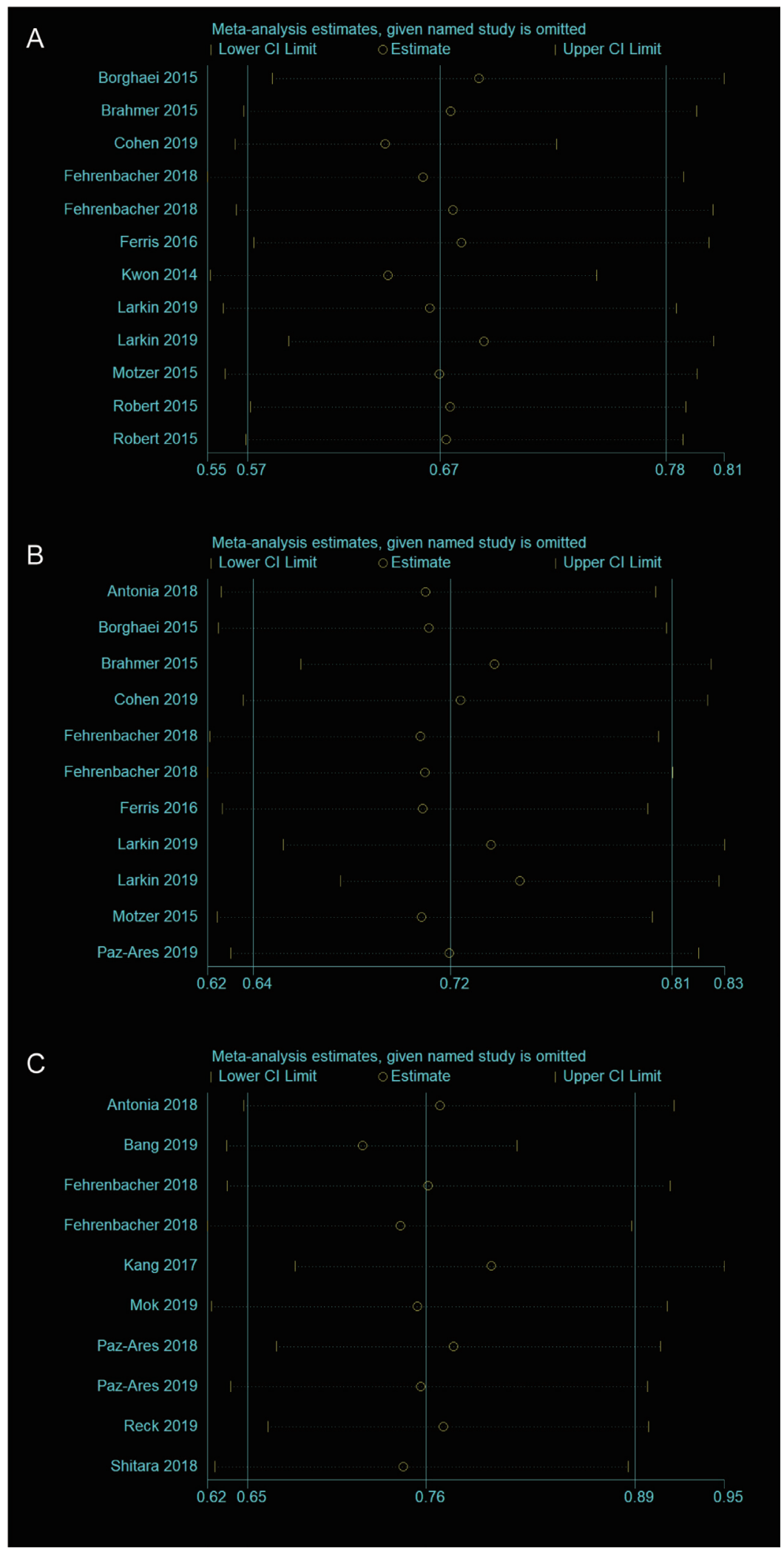

Figure S6 Sensitivity analysis from North American, European, and Asian arms: Sensitivity analysis of overall survival from North American (A), European(B), and Asian (C) arms in included RCTs to determine the robustness of findings in regards to different aspects of trial methodology. 